( 2022 , The Authors. Published by Elsevier Inc. and Fass Inc. on behalf of the American Dairy Science Association ${ }^{\circledR}$. This is an open access article under the CC BY license (http://creativecommons.org/licenses/by/4.0/).

\title{
Invited review: Lethal heat stress: The putative pathophysiology of a deadly disorder in dairy cattle
}

\author{
W. S. Burhans, ${ }^{1 *}$ () C. A. Rossiter Burhans, ${ }^{1} \odot$ and L. H. Baumgard ${ }^{2} \odot$ \\ ${ }^{1}$ Dairy-Tech Group, West Glover, VT 05875 \\ ${ }^{2}$ Department of Animal Science, lowa State University, Ames 50011
}

\section{ABSTRACT}

Heat stress (HS) reduces production and efficiency in almost every metric of the dairy operation, and it thus compromises profitability and sustainability. If the magnitude of HS progresses, it can become lethal. Death can occur acutely or days following the heat load, even if environmental conditions have become nonstressful. Consequently, lethal heat stress (LHS) is often difficult to identify and almost always misdiagnosed. The precise mechanisms of death when dairy cows succumb to LHS has not been fully elucidated or documented, but the pathophysiology of LHS appears to be conserved among several species. The unique digestive physiology of ruminants adds additional layers of complexity that contribute to failure of multiple systems involved with LHS. Consequently, the ostensible etiology and pathogenesis of LHS described herein is extended from the physiological adaptations cows use to survive HS and pertinent pathology extrapolated from other species. The multifactorial causes of death likely involve dysfunction and imbalance of several interdependent systems as follows: (1) electrolyte dyshomeostasis, (2) unstable blood $\mathrm{pH},(3)$ gastrointestinal tract hyperpermeability, (4) sepsis, (5) severe immune activationinduced inflammation, (6) disseminated intravascular hypercoagulation, (7) systemic endothelial permeability, (8) multiple organ failure, and (9) circulatory failure. Having a better understanding of the mechanisms of LHS will improve diagnosis, enable a more accurate prognosis, and provide insight into strategies aimed at preventing dairy cow mortality and morbidity.

Key words: heat stress, disseminated intravascular coagulation, systemic inflammatory response syndrome

Received July 28, 2021.

Accepted January 11, 2022.

*Corresponding author: dr.buzz@dtg-dairynutrition.com

\section{INTRODUCTION}

Most dairy producers, nutritionists, and veterinarians are familiar with heat stress (HS) and aware of how it affects herd performance and farm profitability. Common effects of HS include reduced DMI, decreased milk and component yield, and compromised reproduction (Beede and Collier, 1986; Hahn, 1999; Rhoads et al., 2009), outcomes that incentivize dairy farmers to invest in heat-abatement strategies (e.g., shades, fans, misting or soaking, cross or tunnel ventilation). Although these HS-related manifestations are easily recognized, it is surprising that HS-induced morbidity and mortality are rarely noticed at the individual cow or herd level. Obvious exceptions include unprecedented heat waves that cause mass causalities such as the devastating 2006 California event that killed approximately 40,000 cows. In the last several decades, a plethora of similar lethal heat waves have occurred (Hahn, 1999; Nienaber and Hahn, 2007; Lees et al., 2019). Overall, dairy cow death rates markedly increase when the daily minimum temperature-humidity index exceeds $\sim 70$ (Vitali et al., 2009; Bernabucci et al., 2010), similar to the THI at which mortality increases in pigs (Vitali et al., 2010). However, for most HS-induced cattle fatalities, the actual cause of death is puzzling and elusive. Failure to accurately recognize the presentation and indications of severe HS commonly results in a misdiagnosis, especially following acute HS when environmental conditions are moderate and no longer dangerous (Herbut et al., 2018).

No published literature or veterinary textbooks describe the pathogenesis of morbidity and mortality in dairy cattle attributable to severe HS. Therefore, comparing and contrasting HS-induced pathology among species provides useful insight into why HS can become lethal to dairy cows. In humans that survive heat stroke, HS can cause severe long-term organ dysfunction that increases subsequent chronic comorbidity and mortality risk (Leon and Helwig, 2010). In these patients, the lack of clear ongoing pathophysiological signs severely impedes proper diagnosis and effective treatment, a scenario that almost certainly applies to 
dairy cows currently experiencing or recovering from severe HS.

Heat stress occurs in dairy cattle experiencing unalleviated hyperthermia (caused by both external heat exposure and endogenous heat production), and it stimulates a continuum of behavioral, physiological, and pathological effects that progress as the animal attempts to maintain euthermia. Along this trajectory, physiological responses to a thermal burden are typically referred to as "heat stress" (Bishop-Williams et al., 2015). The term "heat stress" is often imprecisely defined or characterized (West, 2003) and is commonly used to refer to the consequences of elevated heat exposure. However, it is more appropriate to define HS as a condition, as suggested by Leon and Kenefick (2011) as follows: "Heat stress refers to environmental and metabolic conditions that increase body temperature." "Stress" is similarly defined as "an external event or condition" that applies to environmental or thermal "stress" (Collier et al., 2018). Designating HS as "severe" is a description of the relative intensity of the thermal load and accompanying responses, especially when they are extreme enough to become pathological. However, "severe" is also a relative and imprecise categorization because the thermal load at which pathological effects actually occur in individuals is highly variable and influenced by numerous factors that are not easily quantifiable (i.e., prior acclimatization, extent of solar or thermal radiation, microenvironment metrics, frequency and intensity of evaporative cooling, breed, genetics, animal crowding; Hillman et al., 2001; Bohmanova et al., 2007; Gebremedhin et al., 2010). Additionally, preexisting health conditions or congruent infections can intensify the morbidity and mortality response to heat in rodents (Dineen et al., 2021) and ruminants (Silanikove, 2000; Brown-Brandl et al., 2006), a scenario that has practical implications to common dairy cow illnesses (e.g., mastitis or metritis).

Heat stress is a condition; its observable signs and cattle management implications, frequently described in the literature, are not the objective of this paper except as they inform the underlying pathological mechanisms. The focus of this review includes the physiological responses and pathological consequences of HS. As a cow's thermal load increases, the responses progress from subtle behavioral and physiological changes to more observable effects, such as altered performance. When the magnitude of heat load and duration of HS advances, pathologies develop that can become lethal, defined here as "lethal heat stress" (LHS). This response syndrome occurs when an animal cannot cope with HS or mitigate hyperthermia, and lethal pathological and physiological effects ensue. Lethal heat stress does not occur abruptly at some specific threshold or in all animals equally, even in the same herd and facility, nor do the signs of LHS appear at the same degree of HS.

To recognize and differentiate the signs and probable etiologies of LHS, it is necessary to understand the pathophysiology. An essential prerequisite is understanding the pathological sequence of LHS and how physiological responses are interconnected and interdependent. Objectives of this review are to describe the physiology, pathophysiology, and chronology of severe HS response in dairy cows. The pathogenesis is seemingly similar (but not identical) across mammalian species; therefore, when cattle-specific pathology has not been described, examples from other species consistent with the authors' experiences in cattle are cited.

The descriptions of the physiological response to HS and the pathophysiology involved in LHS described herein are based on the following: (1) literature characterizing less severe HS in cattle and other ruminants, (2) generalization of pathophysiology described in the literature for other mammalian species, (3) recent publications regarding HS physiology, and (4) the authors' involvement in LHS and experience with diagnostics and epidemiological approaches to herd and animal level diagnoses. Thus, the characterized pathogenesis we are describing in dairy cows is a putative description because controlled and intervening experimentation is lacking.

\section{GENERAL PHYSIOLOGICAL ASPECTS OF LHS IN DAIRY COWS}

Severe HS effects are more likely to occur when cows are poorly acclimatized, such as early in the summer concomitant with sudden onset of HS (Kadzere et al., 2002; Nienaber and Hahn, 2007). In humans, risk of heat stroke is increased in individuals from cooler regions, indicating differences in acclimatization (Leon and Kenefick, 2011). This is likely the case with LHS risk in cows, explaining LHS in temperate regions such as Canada and northern United States. Severe HS is more likely when extremely high ambient temperatures are coupled with excessive humidity, a combination that reduces the effectiveness of evaporative cooling (i.e., sweating). Severe HS is also more likely when extreme heat loads persist through the entire day and night, or in facilities with inadequate heat abatement. In these scenarios, animals are unable to thermoregulate and become hyperthermic. In LHS cases, multiple responses to hyperthermia develop into acute metabolic and systemic pathologies.

Lethal heat stress pathologies include electrolyte and acid-base derangements, endotoxemia, and physiological perturbations involving respiratory, cardiac, and 
renal dysfunction. Thermal and inflammatory tissue damage occurs, and this is accompanied by extensive systemic inflammation. This becomes a sepsis-like condition called systemic inflammatory response syndrome (SIRS), the result of an exaggerated and extreme immune response to systemic endotoxemia and cellular thermal, oxidative, or anoxic damage. This compromises organ function and causes tissue and cell death (Gyawali et al., 2019). Additionally, SIRS also involves reciprocating immune responses. For example, proinflammatory responses are accompanied by concurrent immunosuppression, and prooxidant responses are concurrent with antioxidant responses. Coagulopathy disorders are another characteristic of LHS. The result of this aberrant pathophysiology is the development of disseminated intravascular coagulation (DIC) leading to organ dysfunction, multiple organ system failures, septic shock, and circulatory failure (low blood pressure and localized perfusion failure). The consequence of this multiple organ dysfunction (MOD) and circulatory failure (albeit difficult to measure in cattle) is often death. Although the mechanistic detail of these LHS elements is beyond the scope here, the chronology, role, and interaction of these pathophysiologies in LHS are described below.

\section{Pathogenic Progression}

Two independent pathways are likely involved in the pathogenesis of LHS in cows, as has been described for the pathogenesis of heat stroke in humans (Lim, 2018). One pathway is "heat toxicity," involving hyperthermia and direct thermal tissue damage. Direct thermolytic effects include liquefaction of cell membranes and denaturation of intracellular proteins and organelles (Lim, 2018). This likely happens in dairy cows, but whether this definitively occurs is technically unknown, as published reports of the histopathology in LHS cases are lacking. The second pathway is identified as "heat sepsis" and involves endotoxemia, oxidative stress, sepsis, bacteremia, and systemic inflammation. In one respect, LHS in cows presents somewhat differently than heat stroke in humans and other animals. In humans and other species (i.e., dogs), in addition to hyperthermia, the diagnosis of heat stroke includes central nervous system dysfunction and lesions (Sprake et al., 2013; Lim, 2018). Although this may occur in cattle, there is no published documentation of nervous system lesions in dairy cows exhibiting fatal hyperthermia.

\section{Initial Heat Load Responses}

Excess body heat accumulation originates from the environment and is exacerbated by metabolic heat production accompanying high feed intake and copious milk production. Cows respond to hyperthermia with physiologic and behavioral attempts to minimize heat production and increase heat dissipation. Decreased feed intake is a consistently recorded behavior during $\mathrm{HS}$ as it is a key component of reducing metabolic heat production (Beede and Collier, 1986), and is generally proportionate to the intensity of the heat load (BrownBrandl et al., 2006). Other behavioral changes to mitigate HS include increased time standing (Cook et al., 2007; Allen et al., 2015) and altered meal patterns (Schneider et al., 1988; Hahn, 1999; Silanikove, 2000; Bernabucci et al., 2010; Conte et al., 2018). Water intake also increases (McDowell et al., 1969; Hahn, 1999; Nienaber and Hahn, 2007; Zimbelman et al., 2010; Alhidary et al., 2012), largely to replenish evaporative water loss (Alhidary et al., 2012; Collier et al., 2018). Inadequate hydration during HS intensifies the progress into LHS for reasons described below. During HS, water intake and total water turnover may actually decrease, both of which are heavily influenced by reduced digestible energy intake and decreased milk yield (Collier et al., 2018). Net water intake, however, is increased when adjusted for milk-free water balance and decreased DMI (Maltz et al., 1994; Silanikove et al., 1997; Kadzere et al., 2002; Collier et al., 2018).

Initial physiological responses to an increased heat load include sweating and respiratory and circulatory adjustments that facilitate evaporative cooling (sweating and respiratory). Sweating is stimulated by skin temperature and is increased by duration of solar exposure and low humidity (Gebremedhin et al., 2010). Solar exposure increases skin temperature that, when applied to a dark coat, can cause skin temperature to rise above core body temperature, a situation that inverts the thermal gradient relative to core body temperature. Multiple factors contribute to the inability to remain euthermic, including high ambient temperatures, exposure to radiant heat, lack of air movement, high humidity, and restricted skin surface area from "bunching" or "huddling" (a behaviorial response that limits convective and radiant heat loss; Whittow, 1965; Berman, 2005). These limitations to evaporative cooling are what dairy producers address with heat-abatement investments. Cows sweat to increase evaporative cooling, more so if the vapor gradient is favorable (Gebremedhin et al., 2010). However, a deficit of electrolyte supply (particularly $\mathrm{K}^{+}$; discussed below) may restrict sweating capacity and thus limit maintenance of homeothermia (Silanikove et al., 1998). When cooling from perspiration is insufficient to restore normal core temperature, cows attempt to cool by increasing their respiration rate $(\mathbf{R R})$ and reducing metabolic heat production (Silanikove, 2000). Mamma- 
lian thermal hyperventilation (increased RR) occurs in 2 stages, the first being thermal tachypnea, involving increased frequency of breathing and a decreased tidal volume. Tachypnea is followed by hyperpnea; high RR and panting continue, but with a reduced frequency of breaths and increased tidal volume compared with the initial tachypnea (Whittow, 1965; Hales and Webster, 1967; Hales, 1973; Robertshaw, 2006; White, 2006). During the hyperpnea stage, arterial hypocapnia occurs, leading to respiratory alkalosis. The change from stage 1 tachypnea to stage 2 hyperpnea occurs when respiration changes from mostly closed-mouth to openmouth panting (Robertshaw, 2006); during stage 1, both types of panting can occur alternately (Hales and Webster, 1967). These physiologic responses are often successful in minimizing HS-induced pathology, but there are limits to the extent that sweating and respiration can dissipate meaningful heat when the heat load is extreme, especially in unacclimatized cattle.

When the heat load increases, blood flow (BF) is redirected to the periphery in an attempt to maximize radiant heat loss (Beede and Collier, 1986; Silanikove, 2000). Increased circulation to the skin (Hales, 1973; Chaseling et al., 2020) is at the expense of BF to splanchnic tissues (Cronje, 2005; Baumgard and Rhoads, 2013), and the extent of gastrointestinal tract (GIT) ischemia parallels increasing heat accumulation (Wang et al., 2011). Independent of HS, reduced DMI during HS also contributes to the GIT hypoperfusion (McGuire et al., 1989; Lough et al., 1990). Several studies demonstrate regional changes in $\mathrm{BF}$ associated with HS in sheep, goats, and young cattle. However, the extent and duration of HS in these studies was usually too brief to affect DMI; thus the driving cause for $\mathrm{BF}$ redistribution during HS is unlikely DMI (Hales, 1973; Choshniak et al., 1982; Bell et al., 1983; Hales et al., 1984; Alexander et al., 1987). Consequently, although the 2 insults (HS and feed restriction) both deleteriously affect GIT barrier function in ruminants and monogastrics (Mayorga et al., 2020), the hyperpermeability effects are more severe in HS (Pearce et al., 2013).

\section{Electrolyte and Acid-Base Derangement}

Electrolyte and acid-base disturbances occur as a consequence to sweating and increased RR. A large amount of $\mathrm{K}^{+}$is secreted in sweat (Kadzere et al., 2002), estimated to be near $12 \%$ of $\mathrm{K}^{+}$intake during HS (West et al., 1987). Potassium secretions in sweat increase with duration of HS and at higher temperatures. Percutaneous $\mathrm{Na}^{+}$secretion also occurs, but at a lower rate than $\mathrm{K}^{+}$, and it also increases with duration of HS (Collier et al., 1982). If dietary $\mathrm{K}^{+}$intake is el- evated compared with requirement fractional excretion of $\mathrm{K}^{+}$increases in urine, although fecal $\mathrm{K}^{+}$excretion is decreased, indicating predominantly renal regulation of surplus $\mathrm{K}^{+}$(West et al., 1987). Aldosterone stimulates $\mathrm{K}^{+}$excretion and $\mathrm{Na}^{+}$retention by the kidney (Rose and Rennke, 1994; Eaton and Pooler, 2004; Verlander, 2020b); however, heat-stressed cows, secreting $\mathrm{K}^{+}$in sweat, have reduced aldosterone levels (El-Nouty et al., 1980). Reduced aldosterone supports $\mathrm{K}^{+}$conservation by increasing renal $\mathrm{K}^{+}$resorption, partly offsetting $\mathrm{K}^{+}$losses in sweat. Conversely, decreased aldosterone level increases renal $\mathrm{Na}^{+}$excretion (Schneider et al., 1984). Decreased aldosterone is also significant because it partially regulates plasma volume, which is initially increased in HS cows (Seif et al., 1973; Silanikove, 2000; Kadzere et al., 2002) due to increased net water intake (adjusted for decreased milk yield).

\section{Respiratory Alkalosis and Compensatory Metabolic Acidosis}

Hyperpnea facilitates evaporative cooling and also causes a reduction in blood $\mathrm{CO}_{2}$ concentration (Hales and Webster, 1967; Robertshaw, 2006; White, 2006), especially during hot daytime hours when HS is more intense (Schneider et al., 1988). This increases blood $\mathrm{pH}$ and results in respiratory alkalosis (Collier et al., 1982; Schneider et al., 1988; Sanchez et al., 1994; Kadzere et al., 2002) consistent with the respiratory bicarbonate-carbon dioxide buffering system (Rose and Rennke, 1994; Robinson, 2002; Ewart, 2020; Verlander, 2020a). Respiratory alkalosis stimulates renal excretion of bicarbonate $\left(\mathrm{HCO}_{3}^{-}\right)$to maintain stable blood $\mathrm{pH}$. This $\mathrm{HCO}_{3}{ }^{-}$loss results in compensatory metabolic acidosis (Sanchez et al., 1994; Kadzere et al., 2002) because the $\mathrm{HCO}_{3}^{-}$excretion is accompanied by $\mathrm{Cl}^{-}$retention and reduced ammoniagenesis. This contributes to a net increase in $\mathrm{Cl}^{-}$-containing acid (eClinpath, 2020) as the $\mathrm{HCO}_{3}^{-}$is exchanged for $\mathrm{Cl}^{-}$by pendrin in the cortical collecting duct. In addition, reduced aldosterone during $\mathrm{HS}$ promotes renal retention of $\mathrm{H}^{+}$, which also contributes to metabolic acidosis (Verlander, 2020a). These electrolyte changes are not confirmed in HS cattle because studies focused on electrolytes often report $\mathrm{Na}^{+}$and $\mathrm{K}^{+}$, but rarely measure $\mathrm{Cl}^{-}$, and because there is limited knowledge of renal control of acid-base balance in domestic animals (Verlander, 2020a). However, this reciprocating acidosis-alkalosis cycle is reflected in cattle by diurnal changes in urinary $\mathrm{pH}$, with increased $\mathrm{pH}$ during the hotter afternoons followed by decreased $\mathrm{pH}$ during the cooler nighttime and early morning (Schneider et al., 1988). Schneider et al. demonstrated that this $\mathrm{pH}$ profile is accompanied by decreasing ammoniagenesis during the hot afternoon, 
consistent with retention of the acid $\mathrm{NH}_{4} \mathrm{Cl}$ (eClinpath, 2020). During the cooler overnight periods, urinary ammonium excretion increases, consistent with reduced plasma acid load. If euthermia is not recovered during the night, the acid-base disturbances are exacerbated. Metabolic acidosis may also further reduce feed intake, as there is a relationship between decreasing blood $\mathrm{pH}$ and reduced DMI (Zimpel et al., 2018).

\section{Sodium Supply Perturbation}

Sodium supply and reserves in HS cattle are likely significantly reduced, although it appears no published study has measured actual $\mathrm{Na}^{+}$or $\mathrm{K}^{+}$balance in cows under severe HS versus thermoneutral environments. Compromised $\mathrm{Na}^{+}$supply is probable for multiple reasons. During HS, decreased DMI reduces $\mathrm{Na}^{+}$intake, and increased RR induces natriuresis (Collier et al., 1982). This renal $\mathrm{Na}^{+}$(a cation) excretion maintains electroneutrality as it occurs concurrently with increased bicarbonate excretion (an anion) and is facilitated by the reduced aldosterone levels during HS (El-Nouty et al., 1980). Renal $\mathrm{Na}^{+}$excretion occurs as fractional $\mathrm{Na}^{+}$extraction increases during extreme heat (Beatty et al., 2006). Excretion is further exacerbated by LPS-induced inflammatory cytokines (released as a result of HS-induced endotoxemia; described below) that dysregulate renal $\mathrm{Na}^{+}$transporters, as demonstrated in a murine model (Schmidt et al., 2007). After sunset when the heat load declines, $\mathrm{Na}^{+}$excretion is markedly reduced, likely because $\mathrm{RR}$ is decreased in the cooler temperatures, $\mathrm{CO}_{2}$ is conserved, and the associated reduced renal $\mathrm{HCO}_{3}{ }^{-}$excretion also conserves $\mathrm{Na}^{+}$. Endotoxemia during HS (discussed below) also reduces $\mathrm{Na}^{+}$supply as it reduces $\mathrm{Na}^{+}$and $\mathrm{Cl}^{-}$absorption from the small intestine (Mani et al., 2012). Diarrhea, frequently observed in cows experiencing HS (Whittow, 1965), can also contribute to metabolic acidosis due to increased loss of fecal $\mathrm{HCO}_{3}{ }^{-}$(Robinson, 2002). Sodium loss is aggravated by diarrhea because a significant portion of body $\mathrm{Na}^{+}$is excreted in feces. However, the largest loss of $\mathrm{Na}^{+}$appears to occur from hypersalivation during panting, which squanders saliva via drooling and slobbering. Saliva "wasting" was estimated to be as much as $18 \mathrm{~kg} / \mathrm{d}$ in heat-stressed cattle (Schneider et al., 1984). Because salivation is largely stimulated by chewing, saliva flow, saliva flux, and saliva loss during panting are likely even more extensive in today's larger and higher-producing cows with higher DMI, compounding the loss of both $\mathrm{Na}^{+}$and $\mathrm{HCO}_{3}{ }^{-}$. As HS intensifies, $\mathrm{Na}^{+}$losses increase (El-Nouty et al., 1980). Eventually, after $\mathrm{Na}^{+}$reserves are greatly diminished, $\mathrm{Na}^{+}$excretion by the kidney as well as a decrease in both saliva volume and $\mathrm{Na}^{+}$content occur, as has been demonstrated in an ovine model of $\mathrm{Na}^{+}$depletion (Denton, 1956).

\section{SALIVA COMPOSITION AND FLUX DURING HS: EFFECT ON SODIUM AND BICARBONATE BALANCE}

Recycling of $\mathrm{Na}^{+}$from saliva to the rumen is dramatically decreased during hyponatremia. In the Denton (1956) ovine $\mathrm{Na}^{+}$depletion study, $\mathrm{Na}^{+}$recycled via saliva was decreased $\sim 79 \%$. Before $\mathrm{Na}^{+}$depletion, daily saliva $\mathrm{K}^{+}$secretion was low $(\sim 31 \mathrm{mEq})$, but with hyponatremia, saliva $\mathrm{K}^{+}$secretion increased $448 \%$. The net $\mathrm{mEq} / \mathrm{L}$ of $\mathrm{Na}^{+}$and $\mathrm{K}^{+}$combined in saliva was maintained at a relatively constant level during $\mathrm{Na}^{+}$depletion due to the inverse changes in proportion of $\mathrm{Na}^{+}$ and $\mathrm{K}^{+}$. However, during $\mathrm{Na}^{+}$depletion, saliva volume decreased $49 \%$. In cattle experiencing HS, the extent to which increased saliva $\mathrm{K}^{+}$content is able to offset decreased salivary $\mathrm{Na}^{+}$flux is unclear because cows also lose $\mathrm{K}^{+}$from sweat and kidneys concurrently with lost $\mathrm{Na}^{+}$. In $\mathrm{Na}^{+}$depletion, some $\mathrm{Na}^{+}$remains available due to renal conservation. During prolonged HS, both $\mathrm{Na}^{+}$ and $\mathrm{K}^{+}$excretion drop precipitously because urinary fractional extraction decreases (Beatty et al., 2006). Older evidence demonstrated that during progressive $\mathrm{Na}^{+}$depletion in hydrated normothermic sheep, urinary excretion of both $\mathrm{Na}^{+}$and $\mathrm{K}^{+}$decreased 99 and 97\%, respectively (Denton, 1956). Importantly, other early work also verified a change, not only in saliva chemistry, but also in rumen fluid electrolyte composition when salivary $\mathrm{Na}^{+}$was removed; in hydrated cows and sheep, rumen $\mathrm{Na}^{+}$concentration decreased, with a reciprocal increase in $\mathrm{K}^{+}$concentration (Scott, 1966; Schneider et al., 1988). Presumably, these changes in conservation are driven by changes in supply and reserves, indicating an increased dietary requirement for both (Sanchez et al., 1994). There is need for an electrolyte balance study in cattle experiencing severe HS to provide data on the magnitude of both $\mathrm{Na}^{+}, \mathrm{K}^{+}$, and $\mathrm{Cl}^{-}$changes in balance and reserves. This is especially needed because the extent of electrolyte depletion is not well-reflected by changes in plasma concentrations, as described below.

\section{Plasma Electrolyte Concentrations}

From an LHS diagnostic perspective, knowing the extent of changes in electrolyte supply would be useful. However, despite reduced $\mathrm{K}^{+}$intake and increased losses during HS, plasma and milk $\mathrm{K}^{+}$concentrations remain relatively unchanged (Schneider et al., 1984, 1986; Beatty et al., 2006), although one earlier study reported milk $\mathrm{K}^{+}$concentrations decreased with HS (Kamal et al., 1961). This apparent maintenance of 
plasma $\mathrm{K}^{+}$concentration is likely facilitated via conservation of $\mathrm{K}^{+}$by the extreme decrease in renal fractional extraction rate observed during HS (Beatty et al., 2006). Similar to $\mathrm{K}^{+}, \mathrm{Na}^{+}$concentration in milk was not decreased in HS cows (Schneider et al., 1986), consistent with earlier work (Kamal et al., 1961). Unchanged plasma $\mathrm{Na}^{+}$concentration during HS was also reported in a heat chamber trial by Schneider et al. (1988). Further evidence that circulatory $\mathrm{Na}^{+}$concentration is typically stable during HS is supported by West et al. (1991), who studied the effect of differences in dietary electrolyte sources during HS and reported that, across a range of diet electrolyte balances, there was no difference in serum $\mathrm{Na}^{+}$concentration $\mathrm{Na}^{+}$was held approximately constant, whereas dietary $\mathrm{K}^{+}$and $\mathrm{Cl}^{-}$were altered). West et al. (1992) further showed that, in heat-stressed cows when DCAD balance varied from 12 to $46 \mathrm{mEq} / 100 \mathrm{~g}$ of $\mathrm{mEq}\left(\mathrm{Na}^{+}+\mathrm{K}^{+}-\mathrm{Cl}^{-}\right)$, neither serum $\mathrm{Na}^{+}$nor $\mathrm{K}^{+}$content differed between DCAD levels or source of cation $\left(\mathrm{NaHCO}_{3}\right.$ vs. $\left.\mathrm{KHCO}_{3}\right)$. Serum $\mathrm{Cl}^{-}$also did not differ across diet DCAD levels nor between $\mathrm{NaHCO}_{3}$ or $\mathrm{KHCO}_{3}$ supplementation. Escobosa et al. (1984) provides additional evidence for the strong homeostatic maintenance of eunatremia and reported that $\mathrm{Na}^{+}$concentrations did not differ in lactating cows fed $0.18 \%, 0.24 \%$, or $0.55 \% \mathrm{Na}^{+}$, and DCAD levels widely varied $\left(\mathrm{Na}^{+}+\mathrm{K}^{+}-\mathrm{Cl}^{-}\right)$at $+19.5,-14.4$, and $+35 \mathrm{mEq} / 100 \mathrm{~g}$, respectively. Overall, these data suggest that differences in supply of either electrolyte may not be sufficiently distinguishable by differences in serum electrolyte concentrations, regardless of temperature or presence of HS. Although the overall body of evidence indicates that there are not physiologically meaningful changes in milk or plasma $\mathrm{Na}^{+}$concentrations, some reports suggest slight statistical decreases in plasma $\mathrm{Na}^{+}$concentrations during $\mathrm{HS}$ (El-Nouty et al., 1980; Schneider et al., 1984, 1986; Beatty et al., 2006). However, in terms of either HS or LHS diagnostics, these changes are not of significant magnitude to be discernable in routine clinical chemistry results where there is no control group comparison.

\section{Sodium Reserve}

Ruminal $\mathrm{Na}^{+}$reserves contribute to stabilizing plasma $\mathrm{Na}^{+}$status. Work by Bell et al. (1981) manipulated $\mathrm{Na}^{+}$supply in cattle and revealed the extent to which the rumen can be a reservoir for $\mathrm{Na}^{+}$and buffer plasma concentrations. These researchers depleted $\mathrm{Na}^{+}$ and $\mathrm{HCO}_{3}{ }^{-}$in young cattle (6-12 mo) by diverting and voiding saliva. Salivary $\mathrm{Na}^{+}$concentration decreased to 35 to $50 \mathrm{mEq} / \mathrm{L}$ and plasma $\mathrm{Na}^{+}$content to just below normal $(128 \mathrm{mEq} / \mathrm{L})$. This reduction in salivary $\mathrm{Na}^{+}$recycled to the rumen resulted in metabolic acidosis. The study revealed that $\mathrm{Na}^{+}$depletion can be associated with metabolic acidosis even when plasma $\mathrm{Na}^{+}$content is only marginally decreased. Replenishing $\mathrm{Na}^{+}$by oral consumption of hypertonic saline increased plasma $\mathrm{Na}^{+}$ from $128 \mathrm{mEq} / \mathrm{L}$ to $136 \mathrm{mEq} / \mathrm{L}$ and increased blood $\mathrm{pH}$. Return to normal plasma $\mathrm{Na}^{+}$concentration was rapid (30 min after consumption of hypertonic saline), indicating a quick transfer from the rumen to extracellular fluid and plasma. In contrast, the recovery of saliva $\mathrm{Na}^{+}$concentration and blood $\mathrm{pH}$ was slower and still subnormal at $\sim 6 \mathrm{~h}$ following hypertonic saline. The fact that these animals were depleted to the point that they evidenced a $\mathrm{Na}^{+}$appetite, yet had only a very modest decrease in plasma $\mathrm{Na}^{+}$, illustrates the strength of homeostatic regulation of plasma $\mathrm{Na}^{+}$.

Although decreased rumen $\mathrm{Na}^{+}$concentration has been demonstrated, decreased whole-body $\mathrm{Na}^{+}$supply, although probable, cannot be confirmed or quantified from previous cattle HS studies. First, plasma concentration is not an amount nor does it denote balance. Second, there are no published $\mathrm{Na}^{+}$balance studies comparing thermoneutral versus HS cows. The authors are aware of $2 \mathrm{Na}^{+}$balance studies in cattle during HS, but neither compared normothermic versus hyperthermic animals (Silanikove and Tadmor, 1989; Silanikove et al., 1997). The increases in $\mathrm{Na}^{+}$and $\mathrm{K}^{+}$requirements suggested by these studies is often not accounted for in diet formulation by dairy nutritionists during severe HS, a failure which can exacerbate LHS pathology.

\section{Water Balance}

Hydration status affects the physiological responses to HS by its effects on plasma volume and osmolality, on respiratory and sweat related cooling, and on the development of coagulopathy. Increased water requirement for cattle experiencing HS is well-recognized (Beede and Collier, 1986; Baker, 1989). Australian work reported that Merino wethers increased water intake $159 \%$ during HS compared with thermoneutral conditions (Alhidary et al., 2012), and other Australian work indicated that heat-stressed nonlactating cattle doubled their water consumption (Beatty et al., 2006). Collier et al. (1982) reported that even a modest increase in temperature from 20 to $30^{\circ} \mathrm{C}$ increased water consumption $29 \%$. Increased water consumption is associated with increased urine volume and decreased urine specific gravity (Beatty et al., 2006), and Beatty et al. also observed decreased packed cell volume, suggesting that increased water intake during HS is associated with increased plasma volume. This is consistent with El-Nouty et al. (1980), who reported that water intake was increased in nonlactating Holstein cattle during HS, accompanied by a modest increase in urine 
output $(+22 \%$ of the increased water intake) along with decreased serum osmolality and total plasma protein. Cows experiencing HS increase milk-free water consumption if water is available (Seif et al., 1973; ElNouty et al., 1980; Schneider et al., 1988; Beatty et al., 2006); subsequently, blood and plasma volume increase.

When adequate water is unavailable or water access is restricted, decreases in plasma and blood volume do not always occur in HS cows, despite a decrease in total body water (Seif et al., 1973). However, in some HS cases, inadequate water intake may decrease plasma volume (El-Nouty et al., 1980) and plasma osmolality can increase. Such decreases in plasma volume can have significant negative effects on cardiovascular function, evaporative cooling, and core body temperature during HS as shown in goats and dairy cows (Baker, 1989; Gebremedhin et al., 2010). Thus, if water intake is limited during HS exposure, cattle can become dehydrated. Progressive dehydration in cows has been associated with increased accumulation of rumen $\mathrm{Na}^{+}$ content of $+5 \mathrm{mEq} / \mathrm{h}$; rumen osmolality increased (281 to 320 mosmol $/ \mathrm{kg}$ ) and rumen fluid $\mathrm{Na}^{+}$concentration increased by $17 \%$ (Silanikove and Tadmor, 1989). With progressive dehydration, rumen volume decreased $51 \%$, and rumen $\mathrm{Na}^{+}$pool size decreased $42 \%(-3,694 \mathrm{mEq}$, $85 \mathrm{~g}$ ). During dehydration, the $\mathrm{Na}^{+}$absorbed from the reticulorumen store was greater than $\mathrm{Na}^{+}$intake by 630\% (Silanikove and Tadmor, 1989), a clear demonstration of the capacity of the rumen $\mathrm{Na}^{+}$reserve to contribute to eunatremia during HS or dehydration. This rumen store of $\mathrm{Na}^{+}$, and the extent to which this $\mathrm{Na}^{+}$is resorbed, could be expected to affect both ruminal VFA absorption and blood $\mathrm{pH}$. There are no reports thoroughly examining rumen $\mathrm{Na}^{+}$flux where euthermic cows are compared with HS cows. Overall, the ruminal fluxes and pools described above raise the question of the extent to which $\mathrm{Na}^{+}$reserve supply is maintained when $\mathrm{Na}^{+}$is lost during HS, and what effect this has on animal wellbeing. Lack of information to answer this question points to the need for an electrolyte balance study comparing euthermic and HS cows, as well as euthermic healthy cows compared with euthermic cows with subacute rumen acidosis.

Insufficient water intake causes dehydration in HS cattle; dehydration can have effects on plasma volume and can contribute to coagulopathy in other species, presumably in bovines as well. In cattle at $30^{\circ} \mathrm{C}$ (moderate HS) in comparison with $20^{\circ} \mathrm{C}$ (the upper range of the thermoneutral zone), water losses increase from urine $(+26 \%)$ and from evaporative cooling as follows: body surfaces $(+176 \%)$ and respiration $(+54 \%$; Collier et al., 1982). Losses are variable with intensity of HS; without adequate water intake to replace the water loss, dehydration occurs. In humans, during even brief
HS, sweating can reduce plasma volume, increase hematocrit and blood viscosity, alter the complete blood count profile, and promote thrombosis (Keatinge et al., 1986). During HS in cattle, the increased water intake described above indicates that a similar loss of body water can occur during heat exposure. Dehydration can also affect cooling. Work in other ruminants (goats) reported that dehydration during short-term heat exposure did not affect respiratory evaporation or RR, but rectal temperature increased and sweating rate decreased compared with well-hydrated goats (Baker, 1989). Earlier work by Baker (1984) showed that dehydrated dogs experiencing HS had higher rectal temperature; they had less effective cooling as indicated by lower RR, reduced respiratory evaporation, and decreased cardiac output. Dehydration in humans decreases cooling by reducing peripheral BF and sweating (Donaldson et al., 2003), and also contributes to cardiac dysfunction, hypotension, and shock (Beker et al., 2018). The aforementioned consequences of dehydration likely occur when HS cattle become dehydrated. This is consistent with a case the authors were involved with where putative LHS deaths occurred in a Jersey herd that had a significant water deficit during only moderate HS (ambient temperatures of $35^{\circ} \mathrm{C}$ ). Clearly, dehydration limits the animal's ability to thermoregulate, increasing the risk of LHS. Thus, there is a need to study the effect of dehydration on thermoregulation mechanisms and mortality outcomes in cattle, as there are a significant number of dairy facilities where cows have inadequate access to water relative to current recommendations such as those proposed by the Wisconsin Dairyland Initiative (https:/ /thedairylandinitiative.vetmed.wisc.edu/home/housing -module/adult-cow-housing/water-space/).

\section{Rumen pH During HS}

Rumen acidosis in feedlot cattle is most common during the summer (Elam, 1976), a seasonal effect that probably also applies to dairy cattle during HS. Rumen $\mathrm{pH}$ is often reported to decrease in HS cows (Mishra et al., 1970; Bandaranayaka and Holmes, 1976; Niles et al., 1980; Collier et al., 1982). The reduction in $\mathrm{pH}$ is likely related to decreased buffering of ruminal VFA caused by decreased $\mathrm{HCO}_{3}{ }^{-}$recycled to the rumen via saliva due to natriuresis, panting, and slobbering as described above. Ruminal $\mathrm{Na}^{+}$and $\mathrm{K}^{+}$supplies are also decreased by reduced saliva flow (West et al., 1987), which contributes to reduced $\mathrm{pH}$ because of a reduced quantity of buffers (sodium and potassium bicarbonates) entering the rumen. The $\mathrm{Na}^{+}$deficit may further reduce rumen $\mathrm{pH}$ by compromising sodium-dependent VFA absorption, described below. Although altered ru- 
men $\mathrm{pH}$ is frequently reported, it is unclear whether ruminal $\mathrm{pH}$ typically decreases in dairy cows during HS events or if it reaches SARA levels. Indeed, a few studies even report that rumen $\mathrm{pH}$ increased during HS (Hall, 2009; Hou et al., 2021).

The lack of clarity on the effect of HS on rumen $\mathrm{pH}$ arises because of the limited number of reports that actually measured rumen $\mathrm{pH}$. Further, in those that did report $\mathrm{pH}$, there are critical differences in trial protocols and execution that affect rumen $\mathrm{pH}$. Notable differences affecting rumen $\mathrm{pH}$ include diet fermentability (Mishra et al., 1970; Gao et al., 2017), duration and frequency of pH measurement (Mishra et al., 1970; Schneider et al., 1988; Hall, 2009; Gao et al., 2017), the duration and extent of the imposed heat load (Gao et al., 2017), hydration status during the measurement period (Mishra et al., 1970; Schneider et al., 1988; Gao et al., 2017), DMI during the study, and differences in diurnal variation in heat exposure (Mishra et al., 1970; Schneider et al., 1988; Gao et al., 2017; Hou et al., 2021). It is also possible that reduced GIT BF during HS may compromise VFA absorption during HS, or that there is an interaction of consumed amounts of either water or DMI that confound the assessment of $\mathrm{pH}$. These differences in trial protocols prevent a clear interpretation of ruminal $\mathrm{pH}$ response to HS.

To complicate our understanding even further, rumen $\mathrm{pH}$ varies over the course of the day (Keunen et al., 2002; Plaizier et al., 2008); however, only a single HS study (Schneider et al., 1988) reported sampling over an entire day (hourly). The definition of SARA is when $\mathrm{pH}$ is below an arbitrary threshold $(5.5,5.6$, or 5.8) for a minimum number of hours; it is not defined as being under a specific $\mathrm{pH}$ threshold for the entire day (Keunen et al., 2002; Plaizier et al., 2008; Zebeli et al., 2008). In almost all studies, the infrequent sampling prevents a thorough evaluation of the diurnal range of $\mathrm{pH}$ because most published HS studies were conducted before the development of indwelling rumen $\mathrm{pH}$ monitors. Because SARA induces endotoxemia, as does severe HS (discussed below), the potential for SARA to exacerbate endotoxemia and its lethal sequelae during LHS should be studied in terms of its contribution to LHS pathogenesis.

Subacute ruminal acidosis can be associated with HS through links to both electrolyte disturbances and systemic acid-base derangement. Up to half of ruminal VFA absorption occurs in a bicarbonate-dependent manner (Dijkstra et al., 2012). Therefore, a $\mathrm{HCO}_{3}{ }^{-}$ deficit could decrease rumen $\mathrm{pH}$ by the following 2 mechanisms: (1) reduced rumen VFA absorption, and (2) reduced proton removal by buffering through the carbonic acid system. Only approximately half of rumen $\mathrm{HCO}_{3}^{-}$originates from saliva; the other half is secreted into the rumen from the ruminal epithelium, exchanged during VFA absorption (Aschenbach et al., 2011). These mechanisms are well-described, but the consequences of $\mathrm{HCO}_{3}{ }^{-}$or $\mathrm{Na}^{+}$deficits for either acidosis or HS are not characterized. One hypothesis is that during severe HS, a reduction in $\mathrm{Na}^{+}$supply through routes described earlier decreases the rumen $\mathrm{HCO}_{3}{ }^{-}$ pool and thus contributes to reduced rumen $\mathrm{pH}$. Additionally, splanchnic hypoperfusion that occurs during HS (described below) also reduces the total $\mathrm{Na}^{+}$flux and reduces the $\mathrm{Na}^{+}$available for maintaining $\mathrm{HCO}_{3}{ }^{-}$ supply, despite the fact that blood $\mathrm{Na}^{+}$concentration appears to be maintained at or close to a normal range during HS (Wang et al., 2011). Inadequate $\mathrm{Na}^{+}$supply would compromise rumen epithelial intracellular $\mathrm{HCO}_{3}{ }^{-}$supply required for VFA exchange and absorption in anionic form because $\mathrm{HCO}_{3}^{-}$is maintained by a $\mathrm{Na}^{+} / \mathrm{HCO}_{3}{ }^{-}$cotransporter that imports $\mathrm{HCO}_{3}{ }^{-}$from circulation (Aschenbach et al., 2011). A deficit of $\mathrm{Na}^{+}$ in HS cows likely also impairs ruminal VFA absorption and removal by a second route whereby protonated VFA are absorbed from the lumen. This mechanism is independent of the $\mathrm{HCO}_{3}{ }^{-}$cotransporter but requires $\mathrm{Na}^{+}$for 2 other reasons. Luminal proton supply available to protonate dissociated VFA proximate to the rumen epithelium is augmented by an apical $\mathrm{Na}^{+} / \mathrm{H}^{+}$ exchanger that ejects intracellular protons into the lumen (Lodemann and Martens, 2006; Aschenbach et al., 2011). Following absorption, protonated VFA are quickly deprotonated. By removing these intracellular protons, the apical $\mathrm{Na}^{+} / \mathrm{H}^{+}$exchanger maintains epithelial cell integrity by stabilizing intracellular $\mathrm{pH}$. Without the excretion of these protons, intracellular $\mathrm{pH}$ would be reduced and intracellular proton accumulation would have deleterious consequences for protein function and cell viability. In addition to the role of $\mathrm{Na}^{+}$ in VFA absorption at the mucosal surface, Aschenbach et al. (2011) and Herdt (2002) indicate multiple other sites in rumen epithelial strata where $\mathrm{Na}^{+}$is involved in VFA and $\mathrm{HCO}_{3}{ }^{-}$transport. Overall, the effects of a reduced supply of $\mathrm{Na}^{+}$and $\mathrm{HCO}_{3}^{-}$during $\mathrm{HS}$ are a presumed reduction in rumen $\mathrm{pH}$ due to decreased salivary $\mathrm{HCO}_{3}{ }^{-}$buffering capacity, less extracellular $\mathrm{HCO}_{3}{ }^{-}$available for $\mathrm{HCO}_{3}{ }^{-}$-dependent dissociated VFA absorption, and reduced VFA absorption and removal arising from decreased ruminal $\mathrm{Na}^{+}$available to remove protons after absorption of undissociated VFA (Aschenbach et al., 2011; Dijkstra et al., 2012). There are no studies assessing the actual net $\mathrm{Na}^{+}$supply or degree of dehydration in prolonged ruminal acidosis or HS, both of which affect cows developing LHS. Data that quantifies and confirms decreased $\mathrm{Na}^{+}$supply and its effect in cows undergoing HS is lacking but merits research efforts during both SARA and HS. 
Additional factors also contribute to reducing rumen $\mathrm{pH}$ during HS. Decreased rumination during HS (Soriani et al., 2013; Moretti et al., 2017) due to reduced DMI and increased RR also contributes to the reduction in rumen $\mathrm{pH}$ (Moallem et al., 2010) because rumination is the primary stimulant of saliva production (Aschenbach et al., 2011). Decreased rumination and rumen $\mathrm{pH}$ both reduce rumen motility (Huber, 1976; Slyter, 1976; Schneider et al., 1988), which decreases mixing proximate to the rumen wall and diminishes VFA removal by absorption. Five days of heat exposure reduced amplitude of rumen motility by $50 \%$, whereas exposure for less than $2 \mathrm{~d}$ had no effect (Attebery and Johnson, 1969). Heat-stressed cows also have altered meal patterns and eat fewer but larger meals than cows in thermal-neutral conditions (Kadzere et al., 2002). Therefore, total feed intake on a daily basis goes down, but the amount of organic matter entering the rumen per meal markedly increases, a scenario that contributes to postprandial reduced rumen $\mathrm{pH}$ (Kadzere et al., 2002; Bernabucci et al., 2010; Conte et al., 2018). In addition to physiological and behavioral reasons, SARA risk is increased in HS cows by management and facility factors (e.g., high pen populations, overcrowding, inadequate water access) by improperly balanced rations (elevated fermentable carbohydrate, inadequate dietary fiber, inadequate electrolyte supplementation) and by poor feeding management [sorting, variable feed times, inadequate feed amounts (i.e., cows running out of feed)]. Clearly, multiple mechanisms contribute to the reduction in rumen $\mathrm{pH}$ that occurs during HS. A reasonable assumption is that conditional on multiple factors, SARA occurs in some severe HS cases and contributes to the pathogenesis of LHS by decreasing GIT barrier function, inducing GIT inflammation, and ultimately endotoxemia (discussed below).

\section{Heat Stress-Induced Gastrointestinal Tract Hyperpermeability}

As already mentioned, during $\mathrm{HS}, \mathrm{BF}$ is reprioritized to peripheral circulation in an attempt to maximize heat dissipation, a priority for remaining euthermic (Beede and Collier, 1986; Silanikove, 2000). To maintain systemic blood pressure, the GIT vasculature vasoconstricts, creating a deficit in splanchnic $\mathrm{BF}$ (Cronje, 2005; Baumgard and Rhoads, 2013), which can be decreased up to $50 \%$ (shown in a rodent and caprine model of HS; Lambert et al., 2002; Wang et al., 2011). This circulatory event results in hypoxia of the intestinal epithelium, which compromises barrier integrity (Hall et al., 1999; Lambert et al., 2002; Chin et al., 2006; Sanz-Fernandez et al., 2014), contributing to a condition colloquially referred to as "leaky gut."
The increased intestinal permeability caused by HS has been shown in multiple mammalian species (Baumgard and Rhoads, 2013), including lactating goats (Wang et al., 2011; Contreras-Jodar et al., 2019) and cows (Koch et al., 2019), and is also implicated as a causal factor in heat stroke in humans (Lim, 2018). Our tenet is that GIT hyperpermeability is etiologically pivotal in how HS progresses into LHS.

Despite being the putative epicenter, the exact mechanism(s) of how HS disrupts GIT barrier function remains elusive. Additionally, the segment within the GIT where hyperpermeability occurs is not clear, and this is especially true in ruminants. The mechanistic and location enigmas are key obstacles in developing dietary mitigation strategies. Regardless, heat stress-induced GIT epithelial hyperpermeability undoubtedly has numerous causes, perhaps including direct thermal damage as in rodents and humans (Bouchama and Knochel, 2002; Lambert et al., 2002). In addition, hypoperfusioninduced hypoxia stimulates IFN- $\gamma$ (interferon $\gamma$ ) and TNF- $\alpha$ (tumor necrosis factor $\alpha$ ) secretion. Both have been shown to decrease intestinal barrier function and increase intestinal epithelial permeability in humans (Taylor et al., 1998); a similar response to hypoxia in bovine intestine seems probable. Another likely cause is intestinal oxidative and nitrosative stress, which occurs during HS (Hall et al., 1999, 2001). Thus, there are almost certainly multiple mechanisms that contribute to "leaky gut" during HS (Lambert et al., 2002; Mayorga et al., 2020).

Another cause of impaired rumen barrier function is cell swelling, which occurs secondary to SARA. Increases in GIT permeability associated with HS occur concomitantly with reduced rumen $\mathrm{pH}$ as described above (Mishra et al., 1970). Increased rumen fluid osmolality postprandially, and more so during SARA, contributes to increased intracellular osmolality in rumen epithelial cells; the consequent cell swelling causes cell death and sloughing (Cronje, 2005). Increased intracellular osmolality during HS also occurs related to splanchnic hypoperfusion, where the lack of oxygen supply to GIT epithelial cells reduces the regeneration of ATP from AMP, resulting in inadequate energy to drive $\mathrm{Na}^{+} / \mathrm{K}^{+}$ pumps that remove intracellular $\mathrm{Na}^{+}$.

During thermal-neutral conditions, rumen histamine production also contributes to epithelial hyperpermeability during reduced ruminal $\mathrm{pH}$ (Aschenbach and Gäbel, 2000; Chang et al., 2018; Gao et al., 2021). Although the mechanism is not conclusive, histamine released from mast cells in the GIT epithelium appear to also cause intestinal hyperpermeability during infection and inflammation induced by endotoxemia (Bischoff, 2009). Gastrointestinal mast cells secrete histamine as well as nitric oxide $\left(\mathrm{NO}^{-}\right)$, cytokines, serine proteases, 
heparin, and prostaglandins as part of mucosal defense from microbial infections and toxins (Penissi et al., 2003; Bischoff, 2009). Mast cell activation may also contribute to stress-induced barrier hyperpermeability, as mast cell secretions (especially the proteases) disrupt intestinal junction proteins and increase paracellular permeability, as has been shown in rodents and pigs (McDermott et al., 2003; Overman et al., 2012; Mayorga et al., 2020). Mast cells may also play a role in reduced GIT motility (De Winter et al., 2012) and contribute to diarrhea (Bischoff, 2009); diarrhea is frequently observed in both SARA- and LHS-affected cattle and in cows intravenously infused with endotoxin (L. H. Baumgard, unpublished observations). Given the similarities, it seems probable that mast cells also contribute to intestinal barrier dysfunction in LHS.

\section{Heat Stress-Induced Endotoxemia}

Endotoxins are not only potent immunogenic molecules once they breach an epithelial barrier, but may themselves also contribute to GIT permeability. Lipopolysaccharide is an endotoxin that compromises the cell wall of gram-negative bacteria and is released when these bacteria die or lyse. Reduced ruminal $\mathrm{pH}$ is accompanied by increased ruminal endotoxin concentrations (Gozho et al., 2007; Tao et al., 2014; Guo et al., 2017), although whether LPS actually directly compromises ruminal barrier function is not clear (Gao et al., 2021). Work by Unno et al. (1997) reported that intravenous LPS administration in rats increased intestinal permeability. Later work by Lambert et al. (2002) demonstrated that HS-induced permeability in rodents was markedly more severe than that induced by intravenous LPS, ostensibly because of heterogeneity of antigens during natural HS. Thus, in cattle, increased luminal LPS concentrations during HS-induced SARA, as well as splanchnic hypoperfusion, probably contribute substantially to a compromised GIT barrier function. Whether luminal LPS actually causes increased epithelial permeability in vivo is not definitive, and this is a key knowledge gap.

The relative contribution of each of the aforementioned mechanisms to compromising GIT barrier function is not clear or definitive, but the combined consequences are that LPS (and undoubtedly many other antigens) infiltrate into local and systemic circulation. Endotoxemia is a consequence of severe HS in lactating cows, and is a well-described sequella of HS in many species, including humans, primates, rats, pigs, and dogs (Leon and Kenefick, 2011; Pearce et al., 2013). Endotoxemia is far more extensively described relative to human heat stroke than to bovine LHS; the ubiquitous occurrence of endotoxemia in nonruminant species suggests that the endotoxin load in cattle experiencing HS is not attributable solely to SARA. Endotoxemia initiates a cascade of systemic inflammation (i.e., a cytokine storm), a development that appears to be a transformative factor in HS initiating LHS. Ruminant endotoxemia leads to activation of widespread defense mechanisms that engender serious and frequently fatal abnormalities, including alterations in cardiovascular function, blood cell profile, vascular permeability, circulatory sufficiency, tissue perfusion, and GIT motility (Constable et al., 2017). Evidence in other species also suggests that systemic endotoxemia is a critical element in whether HS engenders LHS; for instance, pharmacologically neutralizing endotoxin markedly reduced HSassociated mortality in multiple species (Lim, 2018). Interventions that reduce GIT bacterial load decreased circulating LPS and mortality during experimental HS in dogs (Bynum et al., 1979), as did treatment with hyperimmune plasma before inducing HS experimentally in primates (Gathiram et al., 1987). During LHS, endotoxins escape through the GIT epithelium either as cell wall components of live bacteria or as lysed portions of dead microbes (Mani et al., 2012). Luminal endotoxins (and exotoxins) are able to translocate through paracellular spaces when tight junctions between GIT epithelial cells become "loose" (Lambert et al., 2002; Chin et al., 2006; Mani et al., 2012; Guo et al., 2017; Mayorga et al., 2018). If severe enough, not only cellular debris but bacteria themselves are translocated to systemic circulation that can result in bacteremia (Mani et al., 2012). Endotoxin is translocated out of the GIT both from the rumen and from the intestine, with the bulk of LPS appearing to be translocated from the rumen in ruminants (goats; Wang et al., 2011).

Liver dysfunction associated with elevated hepatic endotoxin load is another element in the progression of HS to LHS. Under normal conditions, a small amount of endotoxin infiltrates the GIT barrier and appears in portal circulation, but it is cleared and detoxified by the liver, preventing systemic endotoxemia (Hall et al., 1999, 2001; Wang et al., 2011; Chang et al., 2015). However, as the GIT becomes more permeable and "leaky," increased amounts of endotoxin are translocated into the mesenteric and portal drained viscera (Wang et al., 2011), which increases the burden of endotoxin presenting to the liver. This increased endotoxin delivery can overwhelm the capacity of hepatic Kupffer cells (resident liver macrophages; Dixon et al., 2013) to detoxify the endotoxin. As the endotoxin load presented to the liver increases, or as the duration and severity of HS intensifies, increased amounts of endotoxin escape the liver and enter systemic circulation (Wang et al., 2011; Chang et al., 2015); endotoxemia and sepsis then ensue. 


\section{Hypoalbuminemia}

The elevated hepatic endotoxin load stimulates liver production of acute phase proteins, which occurs at the expense of albumin synthesis (Andersen, 2003). Reduced plasma albumin (a negative acute phase protein) has been reported in dogs that died from HS (Drobatz and Macintire, 1996) and likely occurs because of the intrahepatic repartitioning of AA toward the synthesis of positive acute phase proteins. In dairy cows, albumin concentrations are lowest and globulin concentrations increase during the summer, with the albumin:globulin ratio inverted (0.5, below 1; Roussel et al., 1972). These findings of reduced circulating albumin during hot periods are consistent with the hepatic dysfunction and general inflammation.

\section{Septic Shock}

Another serious pathological consequence of GIT permeability and systemic endotoxemia can be septic shock associated with reperfusion injury, which can occur contingent on the severity of the HS-effected damage (Cronje, 2005). This additional insult is linked to a concurrent increase in oxidative stress, marked by increased production of reactive oxygen species and reactive nitrogen species. Oxidative stress is a consequence of unbalanced activity of pro- and antiinflammatory cytokines stimulated by endotoxins. Enhanced superoxide anion $\left(\mathrm{O}_{2}{ }^{-}\right)$levels are generated in mitochondria during HS, and HS promotes increased transition metal ion formation, which further increases $\mathrm{O}_{2}{ }^{\bullet-}$. This results in increased formation of reactive oxygen species such as hydrogen peroxide $\left(\mathrm{H}_{2} \mathrm{O}_{2}\right)$ and hydroxyl radicals $\left(\mathrm{OH}^{\bullet}\right)$. Hyperthermia also increases $\mathrm{NO}^{-}$production with deleterious consequences, including vasodilation and increased amounts of $\mathrm{O}_{2}{ }^{--}$. Increased $\mathrm{NO}^{-}$, $\mathrm{BF}$ reprioritized to the periphery, and dehydration all impair cardiac function and contribute to hypotension and shock (Beker et al., 2018). Reduced abundance of cellular antioxidants and antioxidant enzymes including glutathione, glutathione peroxidase, and superoxide dismutase also contribute to thermal cytotoxicity and cellular apoptosis during HS (Belhadj Slimen et al., 2014). The cytotoxicity of heat-induced oxidative stress arises from multiple effects, including damaged cellular proteins, reduced ATP production, lipid peroxidation of cell and mitochondrial membranes, and damaged mitochondrial and nuclear DNA. Oxidative stress further damages GIT and hepatic cells and exacerbates the hypoxia-induced GIT permeability, consequently amplifying systemic endotoxemia. Cytokines also cause the release of $\mathrm{NO}^{-}$, a potent vasodilator that causes the vasoconstricted viscera vasculature to vasodilate.
Critically, the now-vasodilated splanchnic bed occurs while the peripheral vasculature is also maximally vasodilated; thus, the animal is unable to maintain blood pressure, resulting in cardiac insufficiency, cardiac failure, and death (i.e., septic shock). This splanchnic reperfusion and systemic low blood pressure likely explain LHS mortality (due to cardiac failure) when it occurs during the peak of hyperthermia (i.e., late afternoon of acute HS).

\section{Systemic Inflammatory Response Syndrome}

A common cause of LHS mortality is the progression of pathogenesis to SIRS and MOD. Sepsis is a hyperinflammatory response to infection; SIRS is an extension of the sepsis definition to include hyperinflammatory immune response to noninfectious causes such as injury, tissue damage due to trauma, hyperthermia, burns, or pancreatitis (Berg and Gerlach, 2018). This includes the typical and expected inflammatory responses seen in severe HS such as thermal damage, toxins, oxidative and nitrosative stress, hypoperfusion-induced ischemia, and related insults that occur consequent to HS. Once released into systemic circulation, endotoxins stimulate release of proinflammatory cytokines, notably TNF- $\alpha$. In cattle with severe HS, the increase in whole-body inflammation progresses into SIRS, a situation in which the inflammatory response is essentially out of control (Jaffer et al., 2010). A simplified explanation of SIRS is that, confronted with either pathogen presence or cell damage, "pathogen-associated molecular patterns" or "damage-associated molecular patterns" activate immune system signaling pathways that induce production of proinflammatory cytokines such as TNF- $\alpha$ and IL-1 $\beta$ (interleukin), which then stimulate synthesis of additional inflammatory mediators (Osterbur et al., 2014). Following the initiation of the inflammatory response, a compensatory antiinflammatory response occurs to prevent the proinflammatory response from being excessive and harmful. When this balance of proand antiinflammation becomes dysregulated, extensive cellular and tissue damage can occur caused by both proinflammatory and antiinflammatory responses. Elevated levels of both pro- and anti-inflammatory cytokines are correlated with organ failure and death in both human and animal models of heat stroke (Bouchama et al., 2005). Systemic inflammatory response syndrome initiates multiple pathologies and indicators; not all elements are necessarily present in every case or at any given time point. Both hyperimmune and hypercoagulation responses are involved in SIRS. Further, this phenomenon is characterized by clinical signs of inflammation, including increased heart rate (tachycardia), increased core body temperature (hyper- 
thermia), increased respiratory rate (tachypnea), and either increased or decreased white blood cell count (leukocytosis or leukopenia; Nyström, 1998; Sanchez, 2015), although body temperature and $\mathrm{PaCO}_{2}$ were decreased in some presentations of SIRS (Nyström, 1998). Due to the permeability of the GIT epithelium during HS, sepsis and bacteremia in cows are likely present. Furthermore, SIRS is typically accompanied by hypotension and coagulation disorders such as DIC and septic shock.

\section{Heat Stress-Induced Coagulopathy}

Another significant aspect of LHS mortality is that SIRS is accompanied by coagulation disorders, especially DIC and microvasculature thrombi, which can cause ischemia and organ dysfunction. Induction of coagulation disorders during HS is clear in a murine model of HS that reported evidence of alterations of complete blood count profiles consistent with dehydration, infection, and immune activation (Proctor et al., 2020). Heat stress stimulates a procoagulant cascade, inducing hypercoagulability indicated by varying degrees of thrombocytopenia and microvascular thrombosis (Gyawali et al., 2019; Proctor et al., 2020); this coagulopathy, described in humans and laboratory animals, appears to occur early after HS onset (Proctor et al., 2020). The procoagulation cascade occurs as levels of thrombin-antithrombin III complexes and soluble fibrin increase, and circulating anticoagulation factors decrease (Hemmelgarn and Gannon, 2013). Some degree of thrombocytopenia is also commonly present in LHS (Gyawali et al., 2019). Heat directly increases platelet aggregation, and coagulation is enhanced in HS in humans and dogs (Leon and Helwig, 2010; Bruchim et al., 2017). In sheep subjected to HS, elevated core body temperature directly activates platelets (Mohanty et al., 1997). Initially, as core temperature increases, hyperaggregation occurs, but hypoaggregation ensues as core body temperature becomes extreme $\left(42.1-43.6^{\circ} \mathrm{C}\right)$. Increased thrombospondin secretion was reported in bovine aortic cells incubated at 41.5 and $43^{\circ} \mathrm{C}$ for $2 \mathrm{~h}$, implying a direct heat effect on thrombosis in cattle, although increased thrombospondin secretion related to heat exposure does not occur in hyperthermic human endothelial cells (Ang and Dawes, 1994). Collectively, LHS initiates a cascade of coagulopathic changes that contribute to DIC.

Similar to the proinflammatory and antiinflammatory responses of SIRS and sepsis, coagulation disorders manifest in LHS to include reciprocate responses as well. Accompanying the hypercoagulation observed in LHS is a reduction in fibrinolysis, exacerbating the hypercoagulation and consequent pathologies. During human SIRS, microvascular thrombosis and hypercoagulation disorders occur, followed by an exaggerated anticoagulation and fibrinolysis response (Leon and Kenefick, 2011). A concurrent fibrinolytic anticoagulation response is initiated. Such hemostatic derangement is described in dogs with heat stroke (Bruchim et al., 2017), but to the authors' knowledge has not been characterized for cattle. Ultimately, the hypercoagulation cascade during LHS produces localized hypoperfusion, tissue hypoxia, and consequent organ dysfunction. In humans, the SIRS inflammatory cascade induces an irreversible cardiac myopathy and consequent cardiac insufficiency. This is accompanied by both arterial and venous microvascular dilation and results in leakage of serous intravascular fluid into the interstitial space. Extravascular leakage causes edema in interstitial spaces, body cavities, and subcutaneous tissues (Gyawali et al., 2019). These phenomena have been observed in the limited cases of LHS reported in both dogs and ruminants affected by HS where congestion in multiple tissues is reported (Terui et al., 1980; Drobatz and Macintire, 1996). This is consistent with the authors' observations of congested vasculature and extensive extravascular fluid, often with significant extravascular fibrin, in cows that died from putative LHS (Figure 1). These observations demonstrate the need for a more thorough description of the histopathology of LHS in dairy cattle.

\section{Vascular Permeability}

In addition to the microvascular leakiness associated with cardiac insufficiency, there are other causes of vascular permeability as well. Although increased gut permeability is well-recognized as an element of HS, increased extrasplanchnic vascular permeability and coagulation disorders are prominent features of SIRS in humans (Ang and Dawes, 1994). However, this has not been described in LHS cattle. Extensive vascular permeability, evidenced as increased amounts of fibrin in the peritoneal, thoracic, and retroperitoneal spaces, is evident in necropsies performed by the authors of cows that died with a putative diagnosis of LHS. This is also consistent with the observation of variable and decreased plasma total protein in heat-stressed cows (El-Nouty et al., 1980); those authors speculated this was a consequence of increased capillary permeability. Vascular permeability is accompanied by vasodilation and the loss of endothelial barrier function (Gyawali et al., 2019). In human cells, extended in vitro exposure beyond $6 \mathrm{~h}$ to $43^{\circ} \mathrm{C}$ disrupted the endothelial barrier such that protein permeability was increased and was no longer selective for specific proteins (Ang and Dawes, 1994). It was speculated that the extended time course 


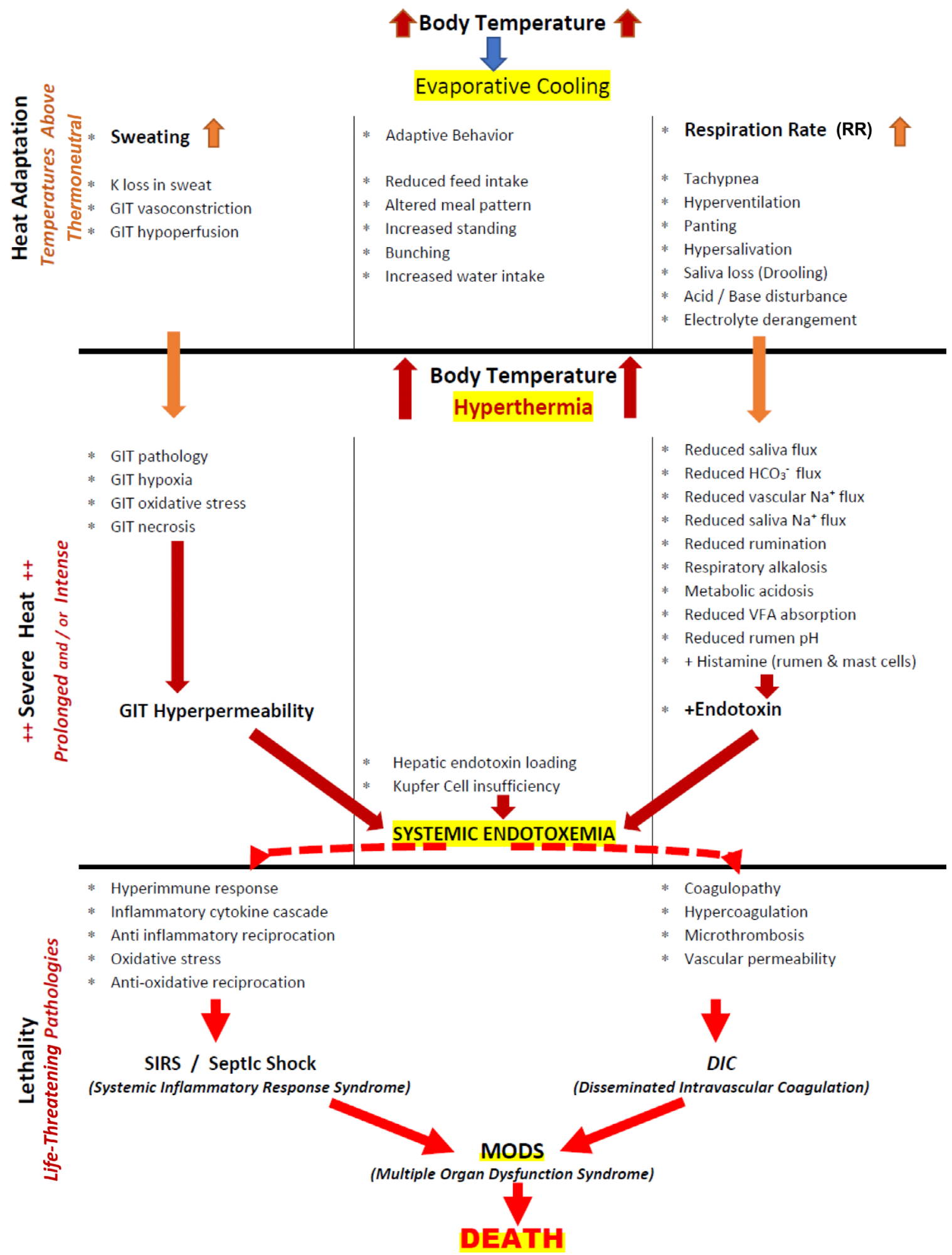

Figure 1. Lethal heat stress in dairy cattle develops in 3 general stages of pathogenic progression. The early response to increased heat exposure is the initiation of evaporative cooling by sweating and increased respiration rate accompanied by behavioral changes (top panel). When heat exposure is intense and extended and the heat load is severe (middle panel) core body temperature increases (hyperthermia) accompanied by abnormal electrolyte and acid base balance physiology. The increase in gastrointestinal tract hyperpermeability results in systemic endotoxemia accompanied by an exaggerated immune response. When the heat burden is not relieved, the hyper-immune activation leads to systemic inflammatory response syndrome and disseminated intravascular coagulation (bottom panel) and inability to maintain homeostasis. Disseminated intravascular coagulation then progresses to lethality. 
before permeability increased might suggest a role for histamine (known to increase vascular permeability) in the release of plasma proteins extravascularly during hyperthermia. Consistent with this speculation, in vitro histamine in human cells induced transient endothelial permeability, the duration of which was prolonged by exposure to thrombin (van Nieuw Amerongen et al., 1998). Interestingly, endotoxins stimulate release of TNF- $\alpha$, which has a procoagulant effect, and has been linked to endothelial injury, endothelial permeability, edema, and septic shock (Royall et al., 1989). In bovine endothelial cells, it was demonstrated that 2 cytokines stimulated by endotoxin (TNF- $\alpha$ and IL-1) increase vascular permeability in a time- and dose-dependent manner (Royall et al., 1989). In vitro, luminal exposure of human venous endothelial cells to TNF- $\alpha$, in the presence of factors responsible for clotting, rapidly enhanced endothelial permeability (Friedl et al., 2002), a finding that supports the posit that endotoxemia increases vascular permeability in bovine LHS cases. In addition to extensive extravascular fibrin observed by the authors in cows that died during HS events, which supports the early initiation of coagulopathy during HS reported by Proctor et al. (2020), necropsies of cows that died at later time points after the acute hyperthermic event showed organized intraperitoneal and intrathoracic fibrinous adhesions between organs and the peritoneal wall. Vascular permeability is a recognized element of SIRS, and SIRS is an element of LHS. Although the exact mechanism is not definitively understood or described in dairy cattle, it is clearly an element of the SIRS response in cattle with LHS.

\section{Multiple Organ Dysfunction}

Systemic inflammatory response syndrome and concomitant coagulopathy ultimately cause MOD, which leads to organ failure and death. Multiple organ dysfunction can be defined as diminished organ function and is associated with acute pathology, leading to failure of organ function to the extent that maintaining homeostasis is not possible without intervention (Nyström, 1998; Osterbur et al., 2014). Multiple organ dysfunction, also called multiple organ dysfunction syndrome (MODS), is difficult to precisely define because consensus definitions of dysfunction in different organ systems do not exist. Nonetheless, MODS is recognized as a sequella to severe SIRS, sepsis, trauma, and HS in humans, primates, laboratory animals, and dogs (Bouchama et al., 2005; Kenney et al., 2010; Leon and Kenefick, 2011; Lim and Suzuki, 2016) and is associated with increased mortality rates. Osterbur et al. (2014) noted in a comparative review of MODS in humans and animals that "there is very little known regard- ing MODS in veterinary species." Even less is known about either SIRS or MODS in large animal production medicine; indeed, an objective of this paper is to raise awareness of MODS with respect to LHS in cattle. There does not appear to be any published descriptions identifying MODS as a sequella of HS in dairy cattle, but necropsies of suspect LHS cases conducted by the authors have revealed organs with micro-thrombi and petechial and ecchymotic hemorrhages, evidence consistent with MODS. The precise pathogenic mechanisms of MODS in cattle is not documented, although several mechanisms, either independently or in concert, have been suggested as follows: cellular hypoxia, cellular apoptosis, translocation of microbes and microbial toxins from the GIT, immune system dysregulation, and mitochondrial dysfunction (Osterbur et al., 2014). All of these mechanisms are likely invoked during LHS, although their relative contribution to MODS in cattle LHS cases is unknown. The particular organs affected by MODS vary with differing cases, but a lack of awareness of how MODS may present in dairy cattle is a serious impediment to diagnosis of putative LHS.

Multiple organ dysfunction syndrome affects the gastrointestinal, hepatic, respiratory, cardiovascular, hematologic, central nervous, adrenal, and renal systems (Osterbur et al., 2014; Bruchim et al., 2017). A manifestation of MODS is consistent with renal tubular and myofibrilar necrosis frequently observed postmortem in heat-stressed animals, including ruminants (Bruchim et al., 2006; Sula et al., 2012; Sprake et al., 2013). In humans, renal failure is an almost universal occurrence in heat stroke patients (Leon and Helwig, 2010). This is consistent with reports of acute renal failure associated with severe inflammation induced experimentally by intraperitoneal LPS in mice (Schmidt et al., 2007). The inflammatory response also includes hepatic inflammation and liver damage (Hall et al., 1999; Guo et al., 2017), and is thought to impair liver function and lead to hepatic steatosis (i.e., fatty liver; Ilan, 2012; SanzFernandez et al., 2014; Mayorga et al., 2018). In fact, it has been proposed that in humans and in animal models of heat stroke, SIRS and sepsis constitute an etiological path to LHS that is considerably independent of thermal damage from heat alone (Lim, 2018). In other words, cellular damage observed in intestines and other organs is not due solely to direct heat damage. It involves a cumulative array of pathologies including endotoxemia and the subsequent combined effects of SIRS and MOD, including poor perfusion, consequent hypoxic necrosis, tissue damage from immune response, metabolic acid-base derangement, endotoxin-induced inflammation, oxidative stress, coagulation disorders, sepsis, and septic shock associated with reperfusion injury. This is consistent with SIRS associated with 
endotoxemia in horses (Hart and Mackay, 2015) and in humans (Leon and Kenefick, 2011; Lim, 2018). In those species, death due to MOD is in many cases a final sequella of the pathophysiological SIRS cascade (Figure 2).
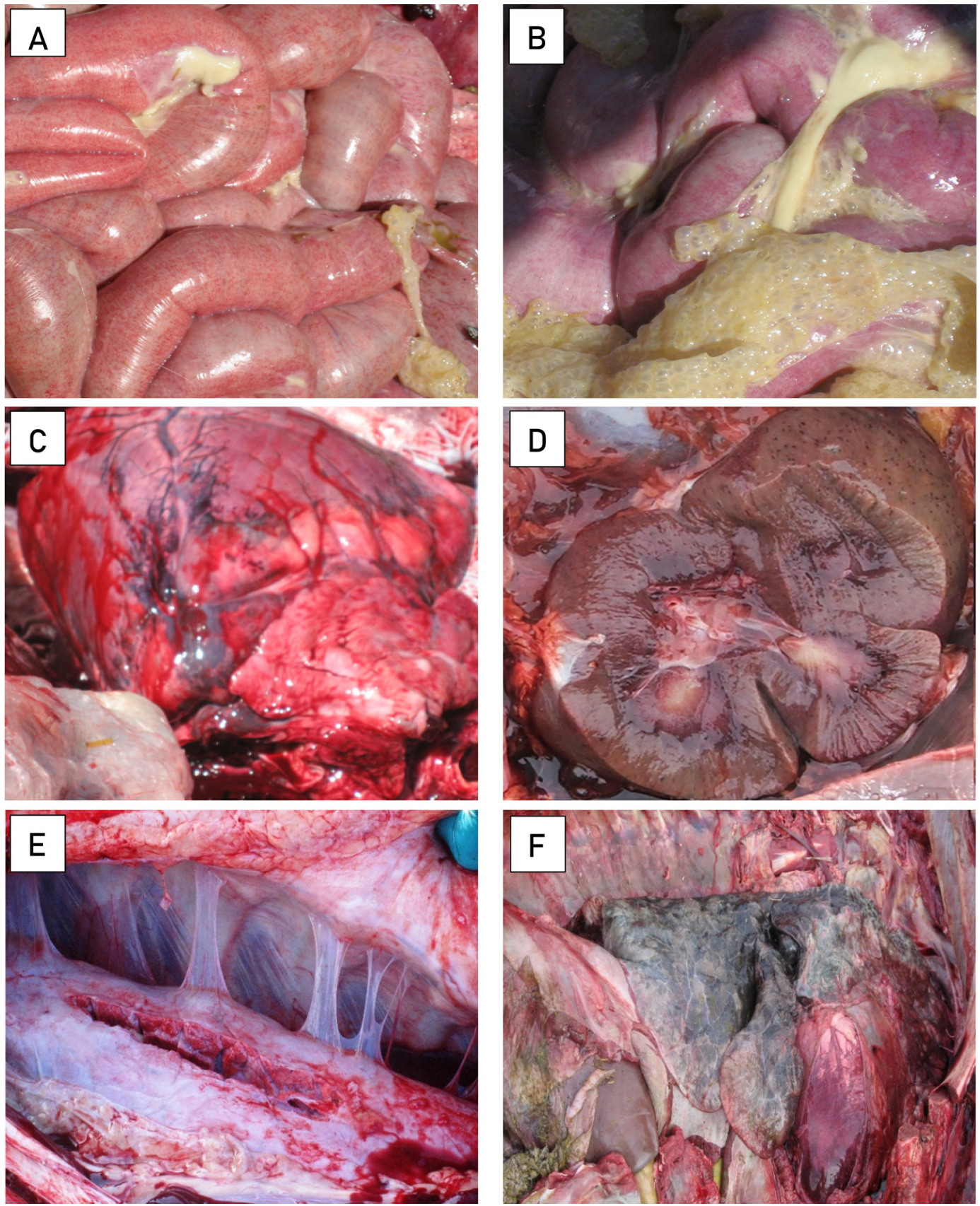

Heat stress can become life threatening or lethal in dairy cows; unfortunately, individual cases are rarely recognized or diagnosed even when cases occur during

Figure 2. Indicative gross postmortem pathologies observed in lethal heat stress-associated dairy cattle deaths [consistent with systemic inflammatory response syndrome (SIRS) and multiple organ dysfunction syndrome (MODS) pathology as described by Ishikawa and Maeda (2013) and Komara et al. (2020)]. A and B: peritoneal extravascular fibrin and visceral petechial hemorrhages consistent with SIRS-related endothelial tight junction permeability and coagulopathy-associated capillary micro-thrombosis. C and D: heart and kidney inflammation and endothelial-associated ecchymotic and petechial hemorrhages, indicative of MODS organ injury and necrosis. E and F: pleural fibrinous effusion, lung edema, and congestion characteristic of end-stage MODS. GIT = gastrointestinal tract. Pictures courtesy of C. Rossiter Burhans, VMD. 
extreme HS. Death frequently occurs days following the extreme heat event, when temperatures are seemingly no longer threatening (Bernabucci et al., 2010). In such cases, the fragmented and unpredictable temporal occurrence between the heat load and death often results in misdiagnosis. The designation "lethal" in the label LHS implies a pathology severe enough to be capable of causing death, although not all cases result in death. Nonetheless, even for survivors, it is a serious pathology that can cause chronic reduced organ function in dairy cows. Although there are extant descriptions of HS effects on dairy cows, the pathophysiology and progression of HS to LHS in dairy cattle has not previously been described in the literature. Several LHS incidences are noted in the literature, including extensive death loss associated with widespread and extreme heat events (Nienaber and Hahn, 2007; Vitali et al., 2009; Baumgard and Rhoads, 2013; Bishop-Williams et al., 2015). However, published references to the more extensive occurrences do not explain LHS presentation, pathology, or differential diagnostics in dairy cattle. Not surprisingly, cattle death due to LHS is almost never recognized as a differential diagnosis when presented in individually or in clusters of death within a herd. There is a need for LHS deaths to be more widely recognized, and for LHS signs to be more clearly described, so a differential diagnosis in field cases can be established. The paucity of information specific to dairy cattle leaves understanding of the pathology largely dependent on studies in other species. Thus, there is a critical need to clarify the signs, indications, and appropriate diagnostics to facilitate accurate field diagnoses of LHS.

\section{ACKNOWLEDGMENTS}

The authors are grateful for the insightful questions raised by the reviewers. Their questions enhanced this review. No external funding was received for this review. The authors have not stated any conflicts of interest.

\section{REFERENCES}

Alexander, G., J. R. Hales, D. Stevens, and J. B. Donnelly. 1987. Effects of acute and prolonged exposure to heat on regional blood flows in pregnant sheep. J. Dev. Physiol. 9:1-15.

Alhidary, I. A., S. Shini, R. Al Jassim, and J. Gaughan. 2012. Physiological responses of Australian Merino wethers exposed to high heat load. J. Anim. Sci. 90:212-220. https://doi.org/10.2527/jas .2011-3972.

Allen, J. D., L. W. Hall, R. J. Collier, and J. F. Smith. 2015. Effect of core body temperature, time of day, and climate conditions on behavioral patterns of lactating dairy cows experiencing mild to moderate heat stress. J. Dairy Sci. 98:118-127. https://doi.org/10 $.3168 /$ jds.2013-7704.

Andersen, P. H. 2003. Bovine endotoxicosis-some aspects of relevance to production diseases. A review. Acta Vet. Scand. 44(Suppl 1):S141. https://doi.org/10.1186/1751-0147-44-S1-S141.
Ang, C., and J. Dawes. 1994. The effects of hyperthermia on human endothelial monolavers: Modulation of thrombotic potential and permeability. Blood Coagul. Fibrinolysis 5:193-199. https://doi .org/10.1097/00001721-199404000-00006.

Aschenbach, J. R., and G. Gäbel. 2000. Effect and absorption of histamine in sheep rumen: Significance of acidotic epithelial damage. J. Anim. Sci. 78:464-470. https://doi.org/10.2527/2000.782464x.

Aschenbach, J. R., G. B. Penner, F. Stumpff, and G. Gabel. 2011. Ruminant Nutrition Symposium: Role of fermentation acid absorption in the regulation of ruminal pH. J. Anim. Sci. 89:1092-1107. https://doi.org/10.2527/jas.2010-3301.

Attebery, J. T., and H. D. Johnson. 1969. Effects of environmental temperature, controlled feeding and fasting on rumen motility. J. Anim. Sci. 29:734-737. https://doi.org/10.2527/jas1969.295734x.

Baker, M. 1984. Cardiovascular and respiratory responses to heat in dehydrated dogs. Am. J. Physiol. Regul. Integr. Comp. Physiol. 246:R369-R374.

Baker, M. 1989. Effects of dehydration and rehydration on thermoregulatory sweating in goats. J. Physiol. 417:421-435.

Bandaranayaka, D. D., and C. W. Holmes. 1976. Changes in the composition of milk and rumen contents in cows exposed to a high ambient temperature with controlled feeding. Trop. Anim. Health Prod. 8:38-46. https://doi.org/10.1007/BF02383364.

Baumgard, L. H., and R. P. Rhoads Jr.. 2013. Effects of heat stress on postabsorptive metabolism and energetics. Annu. Rev. Anim. Biosci. 1:311-337. https://doi.org/10.1146/annurev-animal-031412 $-103644$.

Beatty, D. J., A. Barnes, E. Taylor, D. Pethick, M. McCarthy, and S. Maloney. 2006. Physiological responses of Bos taurus and Bos indicus cattle to prolonged, continuous heat and humidity. J. Anim. Sci. 84:972-985. https://doi.org/10.2527/2006.844972x.

Beede, D., and R. Collier. 1986. Potential nutritional strategies for intensively managed cattle during thermal stress. J. Anim. Sci. 62:543-554. https://doi.org/10.2527/jas1986.622543x.

Beker, B. M., C. Cervellera, A. De Vito, and C. G. Musso. 2018. Human physiology in extreme heat and cold. Int. Arch. Clin. Physiol. 1:001. https://doi.org/10.23937/iacph-2017/1710001.

Belhadj Slimen, I., T. Najar, A. Ghram, H. Dabbebi, M. Ben Mrad, and M. Abdrabbah. 2014. Reactive oxygen species, heat stress and oxidative-induced mitochondrial damage. A review. Int. J. Hyperthermia 30:513-523. https://doi.org/10.3109/02656736.2014 .971446 .

Bell, F. R., P. L. Drury, and J. Sly. 1981. The effect on salt appetite and the renin-aldosterone system on replacing the depleted ions to sodium-deficient cattle. J. Physiol. 313:263-274. https://doi.org/ 10.1113/jphysiol.1981.sp013663.

Bell, A. W., J. R. Hales, R. B. King, and A. A. Fawcett. 1983. Influence of heat stress on exercise-induced changes in regional blood flow in sheep. J. Appl. Physiol. 55:1916-1923.

Berg, D., and H. Gerlach. 2018. Recent advances in understanding and managing sepsis. F1000Res. 7:1570. https://doi.org/10.12688/ f1000research.15758.1.

Berman, A. 2005. Estimates of heat stress relief needs for Holstein dairy cows. J. Anim. Sci. 83:1377-1384. https://doi.org/10.2527/ 2005.8361377x.

Bernabucci, U., N. Lacetera, L. H. Baumgard, R. P. Rhoads, B. Ronchi, and A. Nardone. 2010. Metabolic and hormonal acclimation to heat stress in domesticated ruminants. Animal 4:1167-1183. https: //doi.org/10.1017/S175173111000090X.

Bischoff, S. C. 2009. Physiological and pathophysiological functions of intestinal mast cells. Semin. Immunopathol. 31:185-205. https:// doi.org/10.1007/s00281-009-0165-4.

Bishop-Williams, K. E., O. Berke, D. L. Pearl, K. Hand, and D. F. Kelton. 2015. Heat stress related dairy cow mortality during heat waves and control periods in rural Southern Ontario from 20102012. BMC Vet. Res. 11:291-300. https://doi.org/10.1186/s12917 -015-0607-2.

Bohmanova, J., I. Misztal, and J. B. Cole. 2007. Temperature-humidity indices as indicators of milk production losses due to heat stress. J. Dairy Sci. 90:1947-1956. https://doi.org/10.3168/jds.2006-513. 
Bouchama, A., and J. P. Knochel. 2002. Heat stroke. N. Engl. J. Med. 346:1978-1988.

Bouchama, A., G. Roberts, F. Al Mohanna, R. El-Sayed, B. Lach, S. Chollet-Martin, V. Ollivier, R. Al Baradei, A. Loualich, S. Nakeeb, A. Eldali, and D. de Prost. 2005. Inflammatory, hemostatic, and clinical changes in a baboon experimental model for heatstroke. J. Appl. Physiol. 98:697-705. https://doi.org/10.1152/japplphysiol .00461 .2004 .

Brown-Brandl, T. M., R. A. Eigenberg, and J. A. Nienaber. 2006. Heat stress risk factors of feedlot heifers. Livest. Sci. 105:57-68. https:/ /doi.org/10.1016/j.livsci.2006.04.025.

Bruchim, Y., M. Horowitz, and I. Aroch. 2017. Pathophysiology of heatstroke in dogs - revisited. Temperature (Austin) 4:356-370. https://doi.org/10.1080/23328940.2017.1367457.

Bruchim, Y., E. Klement, J. Saragusty, E. Finkeilstein, P. Kass, and I. Aroch. 2006. Heat Stroke in Dogs: A retrospective study of 54 cases (1999-2004) and analysis of risk factors for death. J. Vet. Intern. Med. 20:38-46.

Bynum, G., J. Brown, D. Dubose, M. Marsili, I. Leav, T. G. Pistole, M. Hamlet, M. LeMaire, and B. Caleb. 1979. Increased survival in experimental dog heatstroke after reduction of gut flora. Aviat. Space Environ. Med. 50:816-819.

Chang, G., L. Wang, N. Ma, W. Zhang, H. Zhang, H. Dai, and X. Shen. 2018. Histamine activates inflammatory response and depresses casein synthesis in mammary gland of dairy cows during SARA. BMC Vet. Res. 14:168. https://doi.org/10.1186/s12917 -018-1491-3.

Chang, G., K. Zhang, T. Xu, D. Jin, H.-M. Seyfert, X. Shen, and S. Zhuang. 2015. Feeding a high-grain diet reduces the percentage of LPS clearance and enhances immune gene expression in goat liver. BMC Vet. Res. 11:67. https://doi.org/10.1186/s12917-015-0376-y.

Chaseling, G. K., C. G. Crandall, and D. Gagnon. 2020. Skin blood flow measurements during heat stress: Technical and analytical considerations. Am. J. Physiol. Regul. Integr. Comp. Physiol. 318:R57-R69.

Chin, A. C., A. N. Flynn, J. P. Fedwick, and A. G. Buret. 2006. The role of caspase-3 in lipopolysaccharide-mediated disruption of intestinal epithelial tight junctions. Can. J. Physiol. Pharmacol. 84:1043-1050. https://doi.org/10.1139/y06-056.

Choshniak, I., D. M. Jenkinson, D. Blatchford, and M. Peaker. 1982. Blood flow and catecholamine concentration in bovine and caprine skin during thermal sweating. Comp. Biochem. Physiol. C Comp. Pharmacol. 7C1:37-42. https://doi.org/10.1016/0306 -4492(82)90007-7.

Collier, R. J., L. H. Baumgard, R. B. Zimbelman, and Y. Xiao. 2018. Heat stress: Physiology of acclimation and adaptation. Anim. Front. 9:12-19. https://doi.org/10.1093/af/vfy031.

Collier, R. J., D. K. Beede, W. W. Thatcher, L. A. Israel, and C. J. Wilcox. 1982. Influences of environment and its modification on dairy animal health and production. J. Dairy Sci. 65:2213-2227. https://doi.org/10.3168/jds.S0022-0302(82)82484-3.

Constable, P. D., K. W. Hinchcliff, S. H. Done, and W. Grunberg. 2017. General systemic states: Toxemia, endotoxemia, and septic shock. Pages 59-67 in Veterinary Medicine. A Textbook of the Diseases of Cattle, Horses, Sheep, Pigs, and Goats. 11th edition. Vol. 1. Elsevier.

Conte, G., R. Ciampolini, M. Cassandro, E. Lasagna, L. Calamari, U. Bernabucci, and F. Abeni. 2018. Feeding and nutrition management of heat-stressed dairy ruminants. Ital. J. Anim. Sci. 17:604620. https://doi.org/10.1080/1828051X.2017.1404944.

Contreras-Jodar, A., N. H. Nayan, S. Hamzaoui, G. Caja, and A. A. Salama. 2019. Heat stress modifies the lactational performances and the urinary metabolomic profile related to gastrointestinal microbiota of dairy goats. PLoS One 14:e0202457. https://doi.org/10 .1371/journal.pone.0202457.

Cook, N. B., R. L. Mentink, T. B. Bennett, and K. Burgi. 2007. The effect of heat stress and lameness on time budgets of lactating dairy cows. J. Dairy Sci. 90:1674-1682. https://doi.org/10.3168/ jds.2006-634.
Cronje, P. B. 2005. Heat stress in livestock-The role of the gut in its aetiology and a potential role for betaine in its alleviation. Recent Advances in Animal Nutrition in Australia 15:107-122.

De Winter, B. Y., R. M. van den Wijngaard, and W. J. de Jonge. 2012. Intestinal mast cells in gut inflammation and motility disturbances. Biochim. Biophys. Acta Mol. Basis Dis. 1822:66-73. https: //doi.org/10.1016/j.bbadis.2011.03.016.

Denton, D. A. 1956. The effect of $\mathrm{Na}+$ depletion on the $\mathrm{Na}+\mathrm{K}+$ ratio of the parotid saliva of the sheep. J. Physiol. 131:516-525. https:/ /doi.org/10.1113/jphysiol.1956.sp005479.

Dijkstra, J., J. L. Ellis, E. Kebreab, A. B. Strathe, S. López, J. France, and A. Bannink. 2012. Ruminal pH regulation and nutritional consequences of low pH. Anim. Feed Sci. Technol. 172:22-33. https:// doi.org/10.1016/j.anifeedsci.2011.12.005.

Dineen, S. M., J. A. Ward, and L. R. Leon. 2021. Prior viral illness increases heat stroke severity in mice. Exp. Physiol. 106:244-257. https://doi.org/10.1113/EP088480.

Dixon, L. J., M. Barnes, H. Tang, M. T. Pritchard, and L. E. Nagy. 2013. Kupffer cells in the liver. Compr. Physiol. 3:785-797. https: //doi.org/10.1002/cphy.c120026.

Donaldson, G. C., W. R. Keatinge, and R. D. Saunders. 2003. Cardiovascular responses to heat stress and their adverse consequences in healthy and vulnerable human populations. Int. J. Hyperthermia 19:225-235.

Drobatz, K. J., and D. K. Macintire. 1996. Heat-induced illness in dogs: 42 cases (1976-1993). J. Am. Vet. Med. Assoc. 209:18941899.

Eaton, D. C., and J. P. Pooler. 2004. Vander's renal physiology. Pages 116-117 in Lange Physiology Series. 6th ed. Lange Medical Books/ McGraw-Hill.

eClinpath. 2020. Acid-base: Types of disturbances. In eClinPath.com. Vol. 2020. T. Stokol, ed. Cornell University College of Veterinary Medicine, Ithaca, NY.

El-Nouty, F. D., I. M. Elbanna, T. P. Davis, and H. D. Johnson. 1980. Aldosterone and ADH response to heat and dehydration in cattle. J. Appl. Physiol. 48:249-255. https://doi.org/10.1152/jappl.1980 .48.2.249.

Elam, C. J. 1976. Acidosis in feedlot cattle: Practical observations. J. Anim. Sci. 43:898-901. https://doi.org/10.2527/jas1976.434898x.

Escobosa, A., C. Coppock, L. Rowe Jr., W. Jenkins, and C. Gates. 1984. Effects of dietary sodium bicarbonate and calcium chloride on physiological responses of lactating dairy cows in hot weather. J. Dairy Sci. 67:574-584. https://doi.org/10.3168/jds.S0022 $-0302(84) 81341-7$.

Ewart, S. L. 2020. Acid-base homeostasis. Pages 584-595 in Cunningham's Textbook of Veterinary Physiology. 6th ed. B. G. Klein, ed. Elsevier.

Friedl, J., M. Puhlmann, D. L. Bartlett, S. K. Libutti, E. N. Turner, M. F. X. Gnant, and H. R. Alexander. 2002. Induction of permeability across endothelial cell monolayers by tumor necrosis factor (TNF) occurs via a tissue factor-dependent mechanism: relationship between the procoagulant and permeability effects of TNF. Blood 100:1334-1339. https://doi.org/10.1182/blood.V100.4.1334 .h81602001334_1334_1339.

Gao, S., A. Zhula, W. Liu, Z. Lu, Z. Shen, G. B. Penner, L. Ma, and D. Bu. 2021. Direct effect of lipopolysaccharide and histamine on permeability barrier of rumen epithelium. Research Squre. https:/ /doi.org/10.21203/rs.3.rs-739646/v1.

Gao, S. T., J. Guo, S. Y. Quan, X. M. Nan, M. V. S. Fernandez, L. H. Baumgard, and D. P. Bu. 2017. The effects of heat stress on protein metabolism in lactating Holstein cows. J. Dairy Sci 100:5040-5049. https://doi.org/10.3168/jds.2016-11913.

Gathiram, P., M. Wells, J. Brock-Utne, and S. Gaffin. 1987. Antilipopolysaccharide improves survival in primates subjected to heat stroke. Circ. Shock 23:157.

Gebremedhin, K. G., C. N. Lee, P. E. Hillman, and R. J. Collier. 2010. Physiological responses of dairy cows during extended solar exposure. Trans. ASABE 53:239-247.

Gozho, G. N., D. O. Krause, and J. C. Plaizier. 2007. Ruminal lipopolysaccharide concentration and inflammatory response during 
grain-induced subacute ruminal acidosis in dairy cows. J. Dairy Sci. 90:856-866. https://doi.org/10.3168/jds.S0022-0302(07)71569 $-2$.

Guo, J., G. Chang, K. Zhang, L. Xu, D. Jin, M. S. Bilal, and X. Shen. 2017. Rumen-derived lipopolysaccharide provoked inflammatory injury in the liver of dairy cows fed a high-concentrate diet. Oncotarget 8:46769-46780. https://doi.org/10.18632/oncotarget.18151.

Gyawali, B., K. Ramakrishna, and A. S. Dhamoon. 2019. Sepsis: The evolution in definition, pathophysiology, and management. SAGE Open Med. 7:2050312119835043. https://doi.org/10.1177/ 2050312119835043.

Hahn, G. L. 1999. Dynamic responses of cattle to thermal heat loads. J. Anim. Sci. 77(Suppl. 2):10-20. https://doi.org/10.2527/1997 .77suppl_210x.

Hales, J. R. 1973. Effects of exposure to hot environments on the regional distribution of blood flow and on cardiorespiratory function in sheep. Pflugers Arch. 344:133-148. https://doi.org/10.1007/ BF00586547.

Hales, J. R. S., A. Bell, A. A. Fawcett, and R. B. King. 1984. Redistribution of cardiac output and skin AVA activity in sheep during exercise and heat stress. J. Therm. Biol. 9:113-116. https://doi .org/10.1016/0306-4565(84)90048-2.

Hales, J., and M. Webster. 1967. Respiratory function during thermal tachypnoea in sheep. J. Physiol. 190:241-260.

Hall, D. M., K. R. Baumgardner, T. D. Oberley, and C. V. Gisolfi. 1999. Splanchnic tissues undergo hypoxic stress during whole body hyperthermia. Am. J. Physiol. Gastrointest. Liver Physiol. 276:G1195-G1203. https://doi.org/10.1152/ajpgi.1999.276.5 G1195.

Hall, D. M., G. R. Buettner, L. W. Oberley, L. Xu, R. D. Matthes, and C. V. Gisolfi. 2001. Mechanisms of circulatory and intestinal barrier dysfunction during whole body hyperthermia. Am. J. Physiol. Heart Circ. Physiol. 280:H509-H521. https://doi.org/10 .1152/ajpheart.2001.280.2.H509.

Hall, M. B. 2009. Heat stress alters ruminal fermentation and digesta characteristics, and behavior in lactating dairy cattle. Page 204 in Proc. 11th Int. Symp. Rumin. Physiol.

Hart, K. A., and R. J. Mackay. 2015. Diseases of the alimentary tract: Endotoxemia and sepsis. Pages 683-695 in Large Animal Internal Medicine. 5th ed. B. P. Smith, ed. Elsevier Mosby.

Hemmelgarn, C., and K. Gannon. 2013. Heatstroke: Thermoregulation, pathophysiology, and predisposing factors. Compend. Contin. Educ. Vet. 35:E4.

Herbut, P., S. Angrecka, and J. Walczak. 2018. Environmental parameters to assessing of heat stress in dairy cattle-A review. Int. J. Biometeorol. 62:2089-2097. https://doi.org/10.1007/s00484-018 $-1629-9$.

Herdt, T. 2002. Digestion: The fermentative process. Pages 280-322 in Textbook of Veterinary Physiology. 3rd ed. W. B. Saunders Company.

Hillman, P., C. Lee, J. Carpenter, K. Baek, and A. Parkhurst. 2001. Impact of hair color on thermoregulation of dairy cows to direct sunlight. Page 1 in Proc. 2001 American Society of Agricultural and Biological Engineers.

Hou, Y., L. Zhang, R. Y. Dong, M. Y. Liang, Y. Lu, X. Q. Sun, and X. Zhao. 2021. Comparing responses of dairy cows to short-term and long-term heat stress in climate-controlled chambers. J. Dairy Sci. 104:2346-2356. https://doi.org/10.3168/jds.2020-18946.

Huber, T. L. 1976. Physiological effects of acidosis on feedlot cattle. J. Anim. Sci. 43:902-909. https://doi.org/10.2527/jas1976.434902x.

Ilan, Y. 2012. Leaky gut and the liver: A role for bacterial translocation in nonalcoholic steatohepatitis. World J. Gastroenterol. 18:2609-2618. https://doi.org/10.3748/wjg.v18.i21.2609.

Ishikawa, T., and H. Maeda. 2013. Systemic Response to Trauma. Pages 47-53 in Encyclopedia of Forensic Sciences. 2nd ed. J. A. Siegel, P. J. Saukko, and M. M. Houck, ed. Academic Press.

Jaffer, U., R. G. Wade, and T. Gourlay. 2010. Cytokines in the systemic inflammatory response syndrome: A review. HSR Proc. Intensive Care Cardiovasc. Anesth. 2:161-175.
Kadzere, C. T., M. R. Murphy, N. Silanikove, and E. Maltz. 2002. Heat stress in lactating dairy cows: A review. Livest. Prod. Sci. 77:59-91. https://doi.org/10.1016/S0301-6226(01)00330-X.

Kamal, T. H., H. D. Johnson, and A. C. Ragsdale. 1961. Influence of the stage of lactation and environmental temperatures on the salt balance of milk. J. Dairy Sci. 44:1655-1667. https://doi.org/10 .3168/jds.S0022-0302(61)89938-4.

Keatinge, W. R., S. R. Coleshaw, J. C. Easton, F. Cotter, M. B. Mattock, and R. Chelliah. 1986. Increased platelet and red cell counts, blood viscosity, and plasma cholesterol levels during heat stress, and mortality from coronary and cerebral thrombosis. Am. J. Med. 81:795-800.

Kenney, E. M., E. A. Rozanski, J. E. Rush, A. M. deLaforcade-Buress, J. R. Berg, D. C. Silverstein, C. D. Montealegre, L. A. Jutkowitz, S. Adamantos, D. H. Ovbey, S. R. Boysen, and S. P. Shaw. 2010. Association between outcome and organ system dysfunction in dogs with sepsis: 114 cases (2003-2007). J. Am. Vet. Med. Assoc. 236:83-87. https://doi.org/10.2460/javma.236.1.83.

Keunen, J. E., J. Plaizier, L. Kyriazakis, T. Duffield, T. Widowski, M. Lindinger, and B. McBride. 2002. Effects of a subacute ruminal acidosis model on the diet selection of dairy cows. J. Dairy Sci. 85:3304-3313. https://doi.org/10.3168/jds.S0022-0302(02)74419 $-6$.

Koch, F., U. Thom, E. Albrecht, R. Weikard, W. Nolte, B. Kuhla, and C. Kuehn. 2019. Heat stress directly impairs gut integrity and recruits distinct immune cell populations into the bovine intestine. Proc. Natl. Acad. Sci. USA 116:10333-10338. https://doi.org/10 $.1073 /$ pnas.1820130116.

Komara, N. L., P. Paragomi, P. J. Greer, A. S. Wilson, C. Breze, G. I. Papachristou, and D. C. Whitcomb. 2020. Severe acute pancreatitis: Capillary permeability model linking systemic inflammation to multiorgan failure. Am. J. Physiol. Gastrointest. Liver Physiol. 319:G573-G583. https://doi.org/10.1152/ajpgi.00285.2020.

Lambert, G. P., C. V. Gisolfi, D. J. Berg, P. L. Moseley, L. W. Oberley, and K. C. Kregel. 2002. Selected contribution: Hyperthermiainduced intestinal permeability and the role of oxidative and nitrosative stress. J. Appl. Physiol. 92:1750-1761. https://doi.org/10 .1152/japplphysiol.00787.2001.

Lees, A. M., V. Sejian, A. L. Wallage, C. C. Steel, T. L. Mader, J. C. Lees, and J. B. Gaughan. 2019. The impact of heat load on cattle. Animals (Basel) 9:322. https://doi.org/10.3390/ani9060322.

Leon, L. R., and B. G. Helwig. 2010. Heat stroke: Role of the systemic inflammatory response. J. Appl. Physiol. 109:1980-1988. https:// doi.org/10.1152/japplphysiol.00301.2010.

Leon, L. R., and R. W. Kenefick. 2011. Pathophysiology of heat-related illnesses. Pages 113-129 in Wilderness Medicine, 6th ed. P. S. Auerbach, T. A. Cushing, and N. S. Harris, ed. Mosby.

Lim, C. L. 2018. Heat sepsis precedes heat toxicity in the pathophysiology of heat stroke- A new paradigm in an ancient disease. Antioxidants 7:149. https://doi.org/10.3390/antiox7110149.

Lim, C. L., and K. Suzuki. 2016. Systemic inflammation mediates the effects of endotoxemia in the mechanisms of heat stroke. Biol Med. (Aligarh) 9:376.

Lodemann, U., and H. Martens. 2006. Effects of diet and osmotic pressure on $\mathrm{Na}+$ transport and tissue conductance of sheep isolated rumen epithelium. Exp. Physiol. 91:539-550. https://doi.org/10 .1113/expphysiol.2005.032078.

Lough, D., D. Beede, and C. Wilcox. 1990. Effects of feed intake and thermal stress on mammary blood flow and other physiological measurements in lactating dairy cows. J. Dairy Sci. 73:325-332. https://doi.org/10.3168/jds.S0022-0302(90)78677-8.

Maltz, E., N. Silanikove, U. Shalit, and A. Berman. 1994. Diurnal fluctuations in plasma ions and water intake of dairy cows as affected by lactation in warm weather. J. Dairy Sci. 77:2630-2639. https:/ /doi.org/10.3168/jds.S0022-0302(94)77204-0.

Mani, V., T. E. Weber, L. H. Baumgard, and N. K. Gabler. 2012. Growth and development symposium: Endotoxin, inflammation, and intestinal function in livestock. J. Anim. Sci. 90:1452-1465. https://doi.org/10.2527/jas.2011-4627. 
Mayorga, E. J., E. A. Horst, M. A. Abeyta, L. M. d. Brink, S. K. Kvidera, M. Al-Quaisi, B. Goetz, R. P. Rhoads, and L. H. Baumgard. 2018. Leaky gut and the glucose costs of immune function. Pages 195-212 in Proc. World Nutrition Forum: S.C.O.P.E. - Scientific Challenges and Opportunities in the Protein Economy. Biomin, Erber AG, Austria.

Mayorga, E. J., J. W. Ross, A. F. Keating, R. P. Rhoads, and L. H. Baumgard. 2020. Biology of heat stress; the nexus between intestinal hyperpermeability and swine reproduction. Theriogenology 154:73-83. https://doi.org/10.1016/j.theriogenology.2020.05.023.

McDermott, J. R., R. E. Bartram, P. A. Knight, H. R. P. Miller, D. R. Garrod, and R. K. Grencis. 2003. Mast cells disrupt epithelial barrier function during enteric nematode infection. Proc. Natl. Acad. Sci. USA 100:7761-7766. https://doi.org/10.1073/ pnas. 1231488100 .

McDowell, R. E., E. G. Moody, P. J. Van Soest, R. P. Lehmann, and G. L. Ford. 1969. Effect of heat stress on energy and water utilization of lactating cows. J. Dairy Sci. 52:188-194. https://doi.org/10 .3168/jds.S0022-0302(69)86528-8.

McGuire, M. A., D. K. Beede, M. A. DeLorenzo, C. J. Wilcox, G. B. Huntington, C. K. Reynolds, and R. J. Collier. 1989. Effects of thermal stress and level of feed intake on portal plasma flow and net fluxes of metabolites in lactating Holstein cows. J. Anim. Sci. 67:1050-1060.

Mishra, M., F. A. Martz, R. W. Stanley, H. D. Johnson, J. R. Campbell, and E. Hilderbrand. 1970. Effect of diet and ambient temperature-humidity on ruminal $\mathrm{pH}$, oxidation reduction potential, ammonia and lactic acid in lactating cows. J. Anim. Sci. 30:10231028. https://doi.org/10.2527/jas1970.3061023x.

Moallem, U., G. Altmark, H. Lehrer, and A. Arieli. 2010. Performance of high-yielding dairy cows supplemented with fat or concentrate under hot and humid climates. J. Dairy Sci. 93:3192-3202. https:/ /doi.org/10.3168/jds.2009-2979.

Mohanty, D., J. Gomez, K. Y. Mustafa, M. Khogali, and K. C. Das. 1997. Pathophysiology of bleeding in heat stress: an experimental study in sheep. Exp. Hematol. 25:615-619.

Moretti, R., S. Biffani, S. Chessa, and R. Bozzi. 2017. Heat stress effects on Holstein dairy cows' rumination. Animal 11:2320-2325. https://doi.org/10.1017/S1751731117001173.

Nienaber, J. A., and G. L. Hahn. 2007. Livestock production system management responses to thermal challenges. Int. J. Biometeorol. 52:149-157. https://doi.org/10.1007/s00484-007-0103-x.

Niles, M., R. Collier, and W. Croom. 1980. Effects of heat stress on rumen and plasma metabolites and plasma hormone concentrations of Holstein cows. J. Anim. Sci. 50(Suppl. 1):152.

Nyström, P. O. 1998. The systemic inflammatory response syndrome: Definitions and aetiology. J. Antimicrob. Chemother. 41(Suppl. A): $1-7$.

Osterbur, K., F. Mann, K. Kuroki, and A. DeClue. 2014. Multiple organ dysfunction syndrome in humans and animals. J. Vet. Intern. Med. 28:1141-1151. https://doi.org/10.1111/jvim.12364.

Overman, E. L., J. E. Rivier, and A. J. Moeser. 2012. CRF induces intestinal epithelial barrier injury via the release of mast cell proteases and TNF- $\alpha$. PLoS One 7:e39935. https://doi.org/10.1371/ journal.pone.0039935.

Pearce, S. C., V. Mani, T. E. Weber, J. W. Ross, R. P. Rhoads, J. F. Patience, L. H. Baumgard, and N. K. Gabler. 2013. The effects of heat stress and plane of nutrition on intestinal integrity and function in growing pigs. J. Anim. Sci. 91:5183-5193.

Penissi, A. B., M. I. Rudolph, and R. S. Piezzi. 2003. Role of mast cells in gastrointestinal mucosal defense. Biocell 27:163-172. https: //doi.org/10.32604/biocell.2003.27.163.

Plaizier, J. C., D. Krause, G. Gozho, and B. McBride. 2008. Subacute ruminal acidosis in dairy cows: the physiological causes, incidence and consequences. Vet. J. 176:21-31. https://doi.org/10.1016/j .tvjl.2007.12.016.

Proctor, E. A., S. M. Dineen, S. C. Van Nostrand, M. K. Kuhn, C. D. Barrett, D. K. Brubaker, M. B. Yaffe, D. A. Lauffenburger, and L. R. Leon. 2020. Coagulopathy signature precedes and predicts severity of end-organ heat stroke pathology in a mouse model.
J. Thromb. Haemost. 18:1900-1910. https://doi.org/10.1111/jth .14875 .

Rhoads, M. L., R. P. Rhoads, M. J. VanBaale, R. J. Collier, S. R. Sanders, W. J. Weber, B. A. Crooker, and L. H. Baumgard. 2009. Effects of heat stress and plane of nutrition on lactating Holstein cows: I. production, metabolism and aspects of circulating somatotropin. J. Dairy Sci. 92:1986-1997. https://doi.org/10.3168/ jds.2008-1641.

Robertshaw, D. 2006. Mechanisms for the control of respiratory evaporative heat loss in panting animals. J. Appl. Physiol. 101:664-668.

Robinson, N. E. 2002. Acid-base homeostasis. Pages 522-532 in Textbook of Veterinary Physiology. 3rd ed. J. G. Cunningham, ed. W. B. Saunders Company.

Rose, B. D., and H. G. Rennke. 1994. Renal pathophysiology - the essentials. Vol. 1. Lippincott Williams \& Wilkins.

Roussel, J. D., K. L. Koonce, and M. A. Pinero. 1972. Relationship of blood serum protein and protein fractions to milk constituents and temperature-season. J. Dairy Sci. 55:1093-1096. https://doi.org/ 10.3168/jds.S0022-0302(72)85630-3.

Royall, J. A., R. L. Berkow, J. S. Beckman, M. K. Cunningham, S. Matalon, and B. A. Freeman. 1989. Tumor necrosis factor and interleukin 1 alpha increase vascular endothelial permeability. Am. J. Physiol. 257:L399-L410. https://doi.org/10.1152/ajplung.1989 .257.6.L399.

Sanchez, L. C. 2015. Manifestation and management of diseases in foals. Pages 243-279 in Large Animal Internal Medicine. 5th ed. B. P. Smith, ed. Elsevier Mosby.

Sanchez, W. K., M. A. McGuire, and D. K. Beede. 1994. Macromineral nutrition by heat stress interactions in dairy cattle: Review and original research. J. Dairy Sci. 77:2051-2079. https://doi.org/10 .3168/jds.S0022-0302(94)77150-2.

Sanz-Fernandez, M. V., S. C. Pearce, N. K. Gabler, J. F. Patience, M. E. Wilson, M. T. Socha, J. L. Torrison, R. P. Rhoads, and L. H. Baumgard. 2014. Effects of supplemental zinc amino acid complex on gut integrity in heat-stressed growing pigs. Animal 8:43-50.

Schmidt, C., K. Höcherl, F. Schweda, A. Kurtz, and M. Bucher. 2007. Regulation of renal sodium transporters during severe inflammation. J. Am. Soc. Nephrol. 18:1072-1083. https://doi.org/10.1681/ ASN.2006050454.

Schneider, P. L., D. Beede, and C. Wilcox. 1988. Nycterohemeral patterns of acid-base status, mineral concentrations and digestive function of lactating cows in natural or chamber heat stress environments. J. Anim. Sci. 66:112-125. https://doi.org/10.2527/ jas1988.661112x.

Schneider, P. L., D. Beede, C. Wilcox, and R. J. Collier. 1984. Influence of dietary sodium and potassium bicarbonate and total potassium on heat-stressed lactating dairy cows. J. Dairy Sci. 67:2546-2553. https://doi.org/10.3168/jds.S0022-0302(84)81611-2.

Schneider, P. L., D. K. Beede, and C. J. Wilcox. 1986. Responses of lactating cows to dietary sodium source and quantity and potassium quantity during heat stress. J. Dairy Sci. 69:99-110. https:// doi.org/10.3168/jds.S0022-0302(86)80374-5.

Scott, D. 1966. The effects of sodium depletion and potassium supplements upon electrical potentials in the rumen of the sheep. Q. J. Exp. Physiol. Cogn. Med. Sci. 51:60-69. https://doi.org/10.1113/ expphysiol.1966.sp001825.

Seif, S. M., H. D. Johnson, and L. Hahn. 1973. Environmental heat and partial water restriction effects on body fluid spaces, water loss, body temperature, and metabolism of Holstein cows. J. Dairy Sci. 56:581-586. https://doi.org/10.3168/jds.S0022-0302(73)85222 -1 .

Silanikove, N. 2000. Effects of heat stress on the welfare of extensively managed domestic ruminants. Livest. Prod. Sci. 67:1-18. https:// doi.org/10.1016/S0301-6226(00)00162-7.

Silanikove, N., E. Maltz, A. Halevi, and D. Shinder. 1997. Metabolism of water, sodium, potassium, and chlorine by high yielding dairy cows at the onset of lactation. J. Dairy Sci. 80:949-956. https:// doi.org/10.3168/jds.S0022-0302(97)76019-3.

Silanikove, N., E. Maltz, D. Shinder, E. Bogin, T. Bastholm, N. J. Christensen, and P. Norggarrd. 1998. Metabolic and productive 
responses of dairy cows to increased ion supplementation at early lactation in warm weather. J. Dairy Res. 65:529-543. https://doi .org/10.1017/S0022029998003185.

Silanikove, N., and A. Tadmor. 1989. Rumen volume, saliva flow rate, and systemic fluid homeostasis in dehydrated cattle. Am. J. Physiol. 256:R809-R815. https://doi.org/10.1152/ajpregu.1989 256.4.R809.

Slyter, L. L. 1976. Influence of acidosis on rumen function. J. Anim. Sci. 43:910-929. https://doi.org/10.2527/jas1976.434910x.

Soriani, N., G. Panella, and L. Calamari. 2013. Rumination time during the summer season and its relationships with metabolic conditions and milk production. J. Dairy Sci. 96:5082-5094. https://doi .org/10.3168/jds.2013-6620.

Sprake, P. M., C. Hubertus, W. T. Bissett, B. F. Porter, K. E. Russell, T. Garland, B. D. Young, and K. E. Washburn. 2013. Neurological disease in lambs associated with exposure to high environmental temperature and humidity. J. Vet. Intern. Med. 27:1242-1247. https://doi.org/10.1111/jvim.12157.

Sula, M. J., C. M. Winslow, M. J. Boileau, L. D. Barker, and R. J. Panciera. 2012. Heat-related injury in lambs. J. Vet. Diagn. Invest. 24:772-776. https://doi.org/10.1177/1040638712445772.

Tao, S., Y. Duanmu, H. Dong, Y. Ni, J. Chen, X. Shen, and R. Zhao. 2014. High concentrate diet induced mucosal injuries by enhancing epithelial apoptosis and inflammatory response in the hindgut of goats. PLoS One 9:e111596. https://doi.org/10.1371/journal.pone .0111596 .

Taylor, C. T., A. L. Dzus, and S. P. Colgan. 1998. Autocrine regulation of epithelial permeability by hypoxia: Role for polarized release of tumor necrosis factor $\alpha$. Gastroenterology 114:657-668. https://doi.org/10.1016/S0016-5085(98)70579-7.

Terui, S., S. Ishino, K. Matsuda, Y. Shoji, K. Ambo, and T. Tsuda 1980. Clinical, hematological and pathological responses in severely heat-stressed steers with special reference to the threshold value for survival. National Institute of Animal Health Quarterly 20:138-147.

Unno, N., H. Wang, M. J. Menconi, S. Tytgat, V. Larkin, M. Smith, M. J. Morin, A. Chavez, R. A. Hodin, and M. P. Fink. 1997. Inhibition of inducible nitric oxide synthase ameliorates endotoxin-induced gut mucosal barrier dysfunction in rats. Gastroenterology 113:1246-1257. https://doi.org/10.1053/gast.1997.v113 .pm9322519.

van Nieuw Amerongen, G. P., R. Draijer, M. A. Vermeer, and V. W. M. van Hinsbergh. 1998. Transient and prolonged increase in endothelial permeability induced by histamine and thrombin. Circ. Res. 83:1115-1123. https://doi.org/10.1161/01.RES.83.11.1115.

Verlander, J. W. 2020a. Acid-base balance. Pages 509-517 in Cunningham's Textbook of Veterinary Physiology. 6th ed. B. G. Klein, ed. Elsevier.

Verlander, J. W. 2020b. Solute reabsorption. Pages 489-508 in Cunningham's Textbook of Veterinary Physiology. 6th ed. B. G. Klein, ed. Elsevier.

Vitali, A., F. Guizzardi, E. Lana, M. Amadori, U. Bernabucci, A. Nardone, and N. Lacetera. 2010. Seasonal pattern of mortality and relationships between mortality and temperature humidity index in heavy slaughter pigs during transport and lairage. Berichte des Meteorologischen Instituts der Albert-Ludwigs-Universität Freiburg. 107

Vitali, A., M. Segnalini, L. Bertocchi, U. Bernabucci, A. Nardone, and N. Lacetera. 2009. Seasonal pattern of mortality and relationships between mortality and temperature-humidity index in dairy cows. J. Dairy Sci. 92:3781-3790. https://doi.org/10.3168/jds.2009 $-2127$.

Wang, L., B. Xue, K. Wang, S. Li, and Z. Li. 2011. Effect of heat stress on endotoxin flux across mesenteric-drained and portaldrained viscera of dairy goat. J. Anim. Physiol. Anim. Nutr. (Berl) 95:468-477.

West, J. W. 2003. Effects of heat-stress on production in dairy cattle. J. Dairy Sci. 86:2131-2144. https://doi.org/10.3168/jds.S0022 -0302(03)73803-X.

West, J. W., C. E. Coppock, K. Z. Milam, D. H. Nave, J. M. Labore, and L. D. Rowe Jr. 1987. Potassium carbonate as a potassium source and dietary buffer for lactating Holstein cows during hot weather. J. Dairy Sci. 70:309-320. https://doi.org/10.3168/jds .S0022-0302(87)80012-7.

West, J. W., K. D. Haydon, B. G. Mullinix, and T. G. Sandifer. 1992. Dietary cation-anion balance and cation source effects on production and acid-base status of heat-stressed cows. J. Dairy Sci. 75:2776-2786. https://doi.org/10.3168/jds.S0022-0302(92)78041 -2 .

West, J. W., B. G. Mullinix, and T. G. Sandifer. 1991. Changing dietary electrolyte balance for dairy cows in cool and hot environments. J. Dairy Sci. 74:1662-1674. https://doi.org/10.3168/jds .S0022-0302(91)78329-X.

White, M. D. 2006. Components and mechanisms of thermal hyperpnea. J. Appl. Physiol. 101:655-663.

Whittow, G. C. 1965. The effect of hyperthermia on the systemic and pulmonary circulation of the ox (Bos taurus). Quarterly J. Exp. Physiol. Cognate Med. Sci. Translation Integration 50:300-311.

Zebeli, Q., J. Dijkstra, M. Tafaj, H. Steingass, B. N. Ametaj, and W. Drochner. 2008. Modeling the adequacy of dietary fiber in dairy cows based on the responses of ruminal $\mathrm{pH}$ and milk fat production to composition of the diet. J. Dairy Sci. 91:2046-2066. https: //doi.org/10.3168/jds.2007-0572.

Zimbelman, R. B., L. H. Baumgard, and R. J. Collier. 2010. Effects of encapsulated niacin on evaporative heat loss and body temperature in moderately heat-stressed lactating Holstein cows. J. Dairy Sci. 93:2387-2394. https://doi.org/10.3168/jds.2009-2557.

Zimpel, R., M. B. Poindexter, A. Vieira-Neto, E. Block, C. D. Nelson, C. R. Staples, W. W. Thatcher, and J. E. P. Santos. 2018. Effect of dietary cation-anion difference on acid-base status and dry matter intake in dry pregnant cows. J. Dairy Sci. 101:8461-8475. https:// doi.org/10.3168/jds.2018-14748.

\section{ORCIDS}

W. S. Burhans (D) https://orcid.org/0000-0003-4362-3753

C. A. Rossiter Burhans (i) https://orcid.org/0000-0001-8702-8548

L. H. Baumgard (D) https://orcid.org/0000-0002-3077-5996 